\title{
Biotic pump of atmospheric moisture as driver of the hydrological cycle on land
}

\author{
A. M. Makarieva and V. G. Gorshkov \\ Petersburg Nuclear Physics Institute, Gatchina, St. Petersburg, Russia \\ Received: 31 March 2006 - Published in Hydrol. Earth Syst. Sci. Discuss.: 30 August 2006 \\ Revised: 15 March 2007 - Accepted: 15 March 2007 - Published: 27 March 2007
}

\begin{abstract}
In this paper the basic geophysical and ecological principles are jointly analyzed that allow the landmasses of Earth to remain moistened sufficiently for terrestrial life to be possible. 1. Under gravity, land inevitably loses water to the ocean. To keep land moistened, the gravitational water runoff must be continuously compensated by the atmospheric ocean-to-land moisture transport. Using data for five terrestrial transects of the International Geosphere Biosphere Program we show that the mean distance to which air fluxes can transport moisture over non-forested areas, does not exceed several hundred kilometers; precipitation decreases exponentially with distance from the ocean. 2 . In contrast, precipitation over extensive natural forests does not depend on the distance from the ocean along several thousand kilometers, as illustrated for the Amazon and Yenisey river basins and Equatorial Africa. This points to the existence of an active biotic pump transporting atmospheric moisture inland from the ocean. 3. Physical principles of the biotic moisture pump are investigated based on the previously unstudied properties of atmospheric water vapor, which can be either in or out of aerostatic equilibrium depending on the lapse rate of air temperature. A novel physical principle is formulated according to which the low-level air moves from areas with weak evaporation to areas with more intensive evaporation. Due to the high leaf area index, natural forests maintain high evaporation fluxes, which support the ascending air motion over the forest and "suck in" moist air from the ocean, which is the essence of the biotic pump of atmospheric moisture. In the result, the gravitational runoff water losses from the optimally moistened forest soil can be fully compensated by the biotically enhanced precipitation at any distance from the ocean. 4. It is discussed how a continent-scale biotic water pump mechanism could be produced by natural selection acting on individual trees. 5. Replacement of the natural forest
\end{abstract}

Correspondence to: A. M. Makarieva

(elba@infopro.spb.su) cover by a low leaf index vegetation leads to an up to tenfold reduction in the mean continental precipitation and runoff, in contrast to the previously available estimates made without accounting for the biotic moisture pump. The analyzed body of evidence testifies that the long-term stability of an intense terrestrial water cycle is unachievable without the recovery of natural, self-sustaining forests on continent-wide areas.

\section{Is it a trivial problem, to keep land moistened?}

Liquid water is an indispensable prerequisite for all life on Earth. While in the ocean the problem of water supply to living organisms is solved, the landmasses are elevated above the sea level. Under gravity, all liquid water accumulated in soil and underground reservoirs inevitably flows down to the ocean in the direction of the maximum slope of continental surfaces. Water accumulated in lakes, bogs and mountain glaciers feeding rivers also leaves to the ocean. So, to accumulate and maintain optimal moisture stores on land, it is necessary to compensate the gravitational runoff of water from land to the ocean by a reverse, ocean-to-land, moisture flow.

When soil is sufficiently wet, productivity of plants and ecological community as a whole is maximized. With natural selection coming into play, higher productivity is associated with higher competitive capacity. Thus, evolution of terrestrial life forms should culminate in a state when all land is occupied by ecological communities functioning at a maximum possible power limited only by the incoming solar radiation. In such a state local stores of soil and underground moisture, ensuring maximum productivity of terrestrial ecological communities, should be equally large everywhere on land irrespective of the local distance to the ocean. Being determined by the local moisture store, local loss of water to river runoff per unit ground surface area should be distanceindependent as well. It follows that in the stationary state the

Published by Copernicus GmbH on behalf of the European Geosciences Union. 
amount of locally precipitating moisture, which is brought from the ocean to compensate local losses to runoff, should be evenly distributed over the land surface.

In the absence of biotic control, air fluxes transporting ocean-evaporated moisture to the continents weaken exponentially as they propagate inland. The empirically established characteristic scale length on which such fluxes are damped out is of the order of several hundred kilometers, i.e. much less than the linear dimensions of the continents. Geophysical atmospheric ocean-to-land moisture fluxes cannot therefore compensate local losses of moisture to river runoff that, on forested territories, are equally high far from the ocean as well as close to it. This means that no purely geophysical explanation can be given to the observed existence of highly productive forest ecosystems on continentscale areas of the order of tens of millions square kilometers, like those of the Amazonia, Equatorial Africa or Siberia.

To ensure functioning of such ecosystems, an active mechanism (pump) is necessary to transport moisture inland from the ocean at a rate dictated by the needs of ecological community. Such a mechanism originated on land in the course of biological evolution and took the form of forest - a contiguous surface cover consisting of tall plants (trees) closely interacting with all other organisms of the ecological community. Forests are responsible both for the initial accumulation of water on continents in the geological past and for the stable maintenance of the accumulated water stores in the subsequent periods of life existence on land. In this paper we analyze the geophysical and ecological principles of the biotic water pump transporting moisture to the continents from the ocean. It is shown that only intact contiguous cover of natural forests having extensive borders with large water bodies (sea, ocean) is able to keep land moistened up to an optimal for life level everywhere on land, no matter how far from the ocean.

The paper is structured as follows. In Sect. 2 the exponential weakening of precipitation with distance from the ocean is demonstrated for non-forested territories using the data for five terrestrial transects of the International Geosphere Biosphere Program (Sect. 2.1); it is shown that no such weakening occurs in natural forests, which points to the existence of the biotic pump of atmospheric moisture (Sect. 2.2); how the water cycle on land is impaired when this pump is broken due to deforestation is estimated in Sect. 2.3. In Sect. 3 the physical principles of the biotic pump functioning are investigated. The non-equilibrium vertical distribution of atmospheric water vapor associated with the observed vertical lapse rate of air temperature (Sect. 3.1) produces an upward directed force, termed evaporative force, which causes the ascending motion of air masses (Sect. 3.2), as well as the horizontal air motions from areas with low evaporation to areas with high evaporation. This physical principle explains the existence of deserts, monsoons and trade winds; it also underlies functioning of the biotic moisture pump in natural forests. Due to the high leaf area index, natural forests maintain powerful evaporation exceeding evaporation from the oceanic surface.

The forest evaporation flux supports ascending fluxes of air and "sucks in" moist air from the ocean. In the result, forest precipitation increases up to a level when the runoff losses from optimally moistened soil are fully compensated at any distance from the ocean (Sect. 3.3). Mechanisms of efficient retention of soil moisture in natural forests are considered in Sect. 3.4. In Sect. 4 it is discussed how the continent-scale biotic pump of atmospheric moisture could be produced by natural selection acting on individual trees. In Sect. 5, based on the obtained results, it is concluded that the long-term stability of a terrestrial water cycle compatible with human existence is unachievable without recovery of natural, selfsustaining forests on continent-wide areas.

\section{Ocean-to-land moisture transport on forested versus non-forested land regions}

\subsection{Moisture fluxes in the absence of biotic control}

Let $F$ be the horizontal moisture flux equal to the amount of atmospheric moisture passing inland across a unit horizontal length perpendicular to the stream line per unit time, dimension $\mathrm{kg} \mathrm{H}_{2} \mathrm{O} \mathrm{m}^{-1} \mathrm{~s}^{-1}$. With air masses propagating inland to a distance $x$ from the ocean ( $x$ is measured along the stream line), their moisture content decreases at the expense of the precipitated water locally lost to runoff. Thus, change of $F$ per unit covered distance is equal to local runoff. In the absence of biotic effects, due to the physical homogeneity of the atmosphere, the probability that water vapor molecules join the runoff, should not depend on the distance traveled by these molecules in the atmosphere. It follows that the change $d F$ of the flux of atmospheric moisture over distance $d x$ should be proportional to the flux itself:

$R(x) \equiv \frac{d F(x)}{d x}=-\frac{1}{l} F(x)$ or $F(x)=F(0) \exp \left\{-\frac{x}{l}\right\}$,

where $R(x)$ is the local loss of water to runoff per unit surface area, $\mathrm{kg} \mathrm{H}_{2} \mathrm{O} \mathrm{m}^{-2} \mathrm{~s}^{-1}, l$ is the mean distance traveled by an $\mathrm{H}_{2} \mathrm{O}$ molecule from a given site to the site where it went to runoff, $F(0)$ is the value of flux $F$ in the initial point $x=0$. Parameter $l$ reflects the intensity of precipitation formation processes (moisture upwelling, condensation and precipitation) (Savenije, 1995); the more rapid they are, the shorter the distance $l$. Moisture recycling (evaporation of water precipitated on land) is also accounted for in the magnitude of parameter $l$.

As far as a certain amount, $E$, of the precipitated water evaporates from the surface and returns to the atmosphere, precipitation $P$ is proportional to, and always higher than, runoff $R$ and can be related to the latter with use of multiplier $k$ (Savenije, 1996a):

$P=E+R \equiv k R, \quad k \geq 1$. 
For example, global runoff constitutes $35 \%$ of terrestrial precipitation (Dai and Trenberth, 2002), which gives a global mean multiplier $k \approx 3$. Equation (1) can then be re-written as

$P(x)=P(0) \exp \left\{-\frac{x}{l}\right\}$ or $\ln P(x)=\ln P(0)-\frac{x}{l}$,

where $P(0)=k R(0)$ is precipitation in the initial point $x=0$. Precipitation is maximal at $x=0$ and declines with increasing $x$.

Linear scale $l$ can be determined from the observed decline of precipitation $P$ with distance $x$ on those territories where the biotic control of water cycle is weak or absent altogether. Such areas are represented by arid low-productive ecosystems with low leaf area index, open canopies and/or short vegetation cover (semideserts, steppes, savannas, grasslands). We collected data on five extensive terrestrial regions satisfying this criterion, i.e. not covered by natural closecanopy forests, Fig. 1. These regions represent the nonforested parts of five terrestrial transects proposed by the International Geosphere Biosphere Program (IGBP) for studying the effects of precipitation gradients under global change (Canadell et al., 2002), Table 1. Within each region distance $x$ was counted in the inland direction approximately perpendicular to the regional isohyets (Savenije, 1995), Fig. 1.

Based on the available meteorological data, the dependence of precipitation $P$ on distance $x$ was investigated in each region, Fig. 2a. In all regions this dependence accurately conforms to the exponential law Eq. (3), which is manifested in the high values of the squared correlation coefficients (0.90-0.99), Table 1. This indicates that the possible dependence on $x$ of multiplier $k$, Eq. (2), which we do not analyze, is weak compared to the main exponential dependence of precipitation $P$ on distance, which is taken into account in Eq. (3). Estimated from parameter $b$ of the linear regression $\ln P=a+b x$ as $l=-1 / b$, see Eq. (3), scale length $l$ takes the values of several hundred kilometers, from $220 \mathrm{~km}$ in Argentina at $31^{\circ} \mathrm{S}$ to $870 \mathrm{~km}$ in the North America, except for region $4 \mathrm{a}$ in Argentina at $45^{\circ} \mathrm{S}$, where $l=93 \mathrm{~km}$, Table 1 . Such a rapid decrease of precipitation has to do with the influence of the high Andean mountain range impeding the movement of westerly air masses coming to the region from the Pacific Ocean (Austin and Sala, 2002). On the island of Hawaii, high ( $>4 \mathrm{~km}$ a.s.l.) mountains also create a large gradient of precipitation which can change more than tenfold over $100 \mathrm{~km}$ (Austin and Vitousek, 2000). In West Africa, the value of $l=400 \mathrm{~km}$ obtained for the areas with $P \leq 1200 \mathrm{~mm}$ year $^{-1}$, Table 1 , compares well with the results of Savenije (1995), who found $l \approx 970 \mathrm{~km}$ for areas with $P \geq 800 \mathrm{~mm}$ year ${ }^{-1}$ and $l \sim 300 \mathrm{~km}$ for the more arid zones of this region.

Total amount of precipitation $\Pi\left(\mathrm{kg} \mathrm{H}_{2} \mathrm{O}\right.$ year $\left.{ }^{-1}\right)$ over the entire path $L \gg l$ traveled by air masses to the inner parts of the continent, $0 \leq x \leq L$, in an area of width $D$ (for river basins

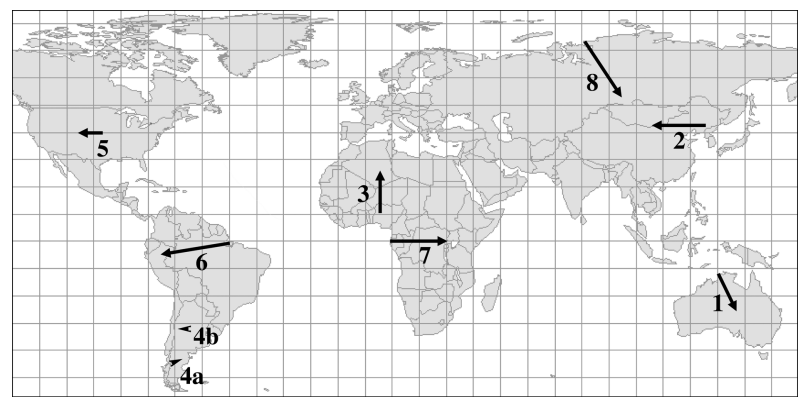

Fig. 1. Geography of the regions where the dependence of precipitation $P$ on distance $x$ from the source of moisture was studied. Numbers near arrows correspond to regions as listed in Table 1. Arrows start at $x=0$ and end at $x=x_{\max }$, see Table 1 for more details.

$D$ can be approximated by the smoothed length of the coastal line) is, due to Eq. (3), equal to

$\Pi=D \int_{0}^{L} P(x) d x \approx P(0) l D$.

As is clear from Eq. (4), $l$ represents a characteristic linear scale equal to the width of the band of land adjacent the coast which would be moistened by the incoming oceanic air masses if the precipitated moisture were uniformly distributed over $x$ with a density $P(0)$. For land areas with ordinary orography (regions $1-3,4 \mathrm{~b}, 5$ ) the mean value of $l$ is about $600 \mathrm{~km}$, Table 1, i.e. it is significantly smaller than the characteristic horizontal dimensions of the continents. Thus, in the absence of biotic control the transport of moisture to land would only be able to ensure normal life functioning in a narrow band near the ocean of a width not exceeding several hundred kilometers; the much more extensive inner parts of the continents would have invariably remained arid. Already at this stage of our consideration we come to the conclusion that in order to explain the observed existence of the extensive well-moistened continental areas several thousand kilometers in length (the Amazon river basin, Equatorial Africa, Siberia), where natural forests are still functioning (Bryant et al., 1997), it is necessary to involve a different, biotically controlled mechanism of ocean-to-land moisture transport.

\subsection{Biotic pump of atmospheric moisture}

Let us now consider the spatial distribution of precipitation on extensive territories covered by natural forests. As far as soil moisture content ultimately dictates life conditions for all species in the ecological community, functioning of the community should be aimed at keeping soil moisture at a stationary level optimal for life. Maintenance of high soil moisture content $W$ (units $\mathrm{kg} \mathrm{H}_{2} \mathrm{O} \mathrm{m}^{-2}=\mathrm{mm} \mathrm{H}_{2} \mathrm{O}$ ) enables the ecological community to achieve high power of functioning even when the precipitation regime is fluctuating. For example, transpiration of natural forests in the Amazon river basin, where soil moisture content is high throughout 
Table 1. Precipitation on land $P\left(\mathrm{~mm}_{\text {year }}{ }^{-1}\right)$ versus distance from the source of moisture $x(\mathrm{~km})$ as dependent on the absence/presence of natural forests

\begin{tabular}{|c|c|c|c|c|c|c|c|c|c|}
\hline \multicolumn{5}{|c|}{ Region } & \multicolumn{5}{|c|}{ Parameters of linear regression ${ }^{1} \ln P=a-b x$} \\
\hline No & Name & $\begin{array}{c}x=0 \\
{ }^{\circ} \text { Lat, }{ }^{\circ} \text { Lon }\end{array}$ & $\begin{array}{c}x=x_{\max } \\
{ }^{\circ} \text { Lat, }{ }^{\circ} \text { Lon }\end{array}$ & $\begin{array}{r}x_{\max }, \\
\mathrm{km}\end{array}$ & $a \pm 1$ s.e. & $\begin{array}{c}(b \pm 1 \text { s.e. }) \\
\times 10^{3}\end{array}$ & $r^{2}$ & $\begin{array}{r}P(0) \equiv e^{a}, \\
\text { mm year }^{-1}\end{array}$ & $\begin{array}{r}l \equiv 1 / b, \\
\mathrm{~km}\end{array}$ \\
\hline & Non-forested regions ${ }^{2}$ & & & & & & & & \\
\hline 1 & North Australia ${ }^{3}$ & $-11.3,130.5$ & $-25,137$ & 1400 & $7.37 \pm 0.05$ & $1.54 \pm 0.06$ & 0.96 & 1600 & 650 \\
\hline 2 & North East China ${ }^{4}$ & 42,125 & 42,107 & 1500 & $6.67 \pm 0.08$ & $1.24 \pm 0.10$ & 0.96 & 790 & 800 \\
\hline 3 & West Africa ${ }^{5}$ & 10,5 & 25,5 & 1650 & $7.28 \pm 0.09$ & $2.46 \pm 0.09$ & 0.99 & 1450 & 400 \\
\hline $4 \mathrm{a}$ & Argentina ${ }^{6}, 45^{\circ} \mathrm{S}$ & $-44.8,-71.7$ & $-45,-69.8$ & 150 & $6.36 \pm 0.17$ & $10.8 \pm 2.0$ & 0.90 & 580 & 93 \\
\hline $4 \mathrm{~b}$ & Argentina $^{6}, 31^{\circ} \mathrm{S}$ & $-31.3,-65.3$ & $-31.7,-68.3$ & 360 & $6.35 \pm 0.12$ & $4.57 \pm 0.59$ & 0.91 & 570 & 220 \\
\hline 5 & North America ${ }^{7}$ & $39.8,-96.7$ & $41.2,-105.5$ & 750 & $6.69 \pm 0.04$ & $1.15 \pm 0.08$ & 0.93 & 800 & 870 \\
\hline & Natural forests 8 & & & & & & & & \\
\hline 6 & Amason river basin 9 & $0,-50$ & $-5,-75$ & 2800 & $7.76 \pm 0.04$ & $-0.05 \pm 0.02$ & 0.13 & 2300 & $-2 \times 10^{4}$ \\
\hline 7 & Congo river basin ${ }^{10}$ & 0,9 & 0,30 & 2300 & $7.56 \pm 0.17$ & $-0.10 \pm 0.12$ & 0.05 & 1900 & $-1 \times 10^{4}$ \\
\hline 8 & Yenisey river basin ${ }^{11}$ & $73.5,80.5$ & $50.5,95.5$ & 2800 & $6.06 \pm 0.17$ & $-0.01 \pm 0.10$ & 0.05 & 430 & $-1 \times 10^{4}$ \\
\hline
\end{tabular}

Notes:

${ }^{1}$ Statistics are significant at the probability level $p<0.0001$ for regions $1,2,3$ and 5 ; $p=0.013$ for region $4 \mathrm{a}$ and $p<0.001$ for region $4 \mathrm{~b}$; $p \geq 0.05$ for regions 6,7 and 8 (i.e., there is no exponential dependence of $P$ on $x$ in these regions).

2 Regions 1, 2, 3, 4 (a and b) and 5 correspond to the non-forested parts of the North Australian Tropical Transect, North East China Transect (NECT), Savannah on the Long-Term Transect, Argentina Transect and North American Mid-Latitude Transect of the International Geosphere Biosphere Program, respectively (Canadell et al., 2002).

3 Precipitation data for $x=0$ (Prilangimpi, Australia) taken from Cook and Heerdegen (2001), all other data taken from Fig. 2a of Miller et al. (2001) assuming $1^{\circ}$ Lat. $=110 \mathrm{~km}$.

${ }^{4}$ Data taken for $42^{\circ} \mathrm{N}$ of NECT, because at this latitude NECT comes most closely to the ocean. Location of $x=0$ approximately corresponds to the border between forest and steppe zones; the dependence between $P$ and $x$ obtained from the location of isohyets taken from Fig. $3 \mathrm{c}$ of $\mathrm{Ni}$ and Zhang (2000) assuming $10^{\circ}$ Lon. $=825 \mathrm{~km}$ at $42^{\circ} \mathrm{N}$.

5 Southern border of the non-forested part of West Africa approximately coincides with the 1200 mm isohyet, hence the choice of $x=0$ at $10^{\circ} \mathrm{N} 5^{\circ} \mathrm{E}$, where $P=1200 \mathrm{~mm}_{\text {year }}{ }^{-1}$. The dependence between $P$ and $x$ was obtained from the location of isohyets taken from Fig. 2 of Nicholson (2000) assuming $1^{\circ}$ Lat. $=110 \mathrm{~km}$.

${ }^{6}$ Data for region 4a and 4b taken from Table 1 of Austin and Sala (2002) and Figs. 1 and 2 of Cabido et al. (1993), respectively. In region $4 \mathrm{~b}$ atmospheric moisture comes from the Pacific Ocean (Austin and Sala, 2002), in region 4a the ultimate source of moisture is the Atlantic Ocean (Zhou and Lau, 1998), hence the opposite directions of counting $x$ in the two regions.

${ }^{7}$ Data taken from Table 1 of Barrett et al. (2002), $x$ calculated assuming $1^{\circ}$ Lat. $=110 \mathrm{~km}$.

8 Precipitation values for the three regions covered by natural forests are taken from the data sets distributed by the University of New Hampshire, EOS-WEBSTER Earth Science Information Partner (ESIP) at http://eos-webster.sr.unh.edu. Regions 6 and 8 correspond to the Amazon (LBA) and Central Siberia Transect of IGBP, respectively (Canadell et al., 2002).

${ }^{9}$ Precipitation data taken from the gridded monthly precipitation data bank LBA-Hydronet v1.0 (Water Systems Analysis Group, Complex Systems Research Center, University of New Hampshire), time period 1960-1990, grid size 0.5×0.5 degrees (Webber and Wilmott, 1998); statistics is based on $P$ values for 26 grid cells that are crossed by the straight line from $x=0$ to $x=x_{\max }$, Fig. 1 .

10 The transect was chosen in the center of the remaining natural forest area in the Equatorial Africa (Bryant et al., 1997). Precipitation data taken from the gridded annual precipitation data bank of the National Center for Atmospheric Research (NCAR)'s Community Climate System Model, version 3 (CCSM3), time period 1870-1999, grid size $1.4 \times 1.4$ degrees; statistics is based on $P$ values for 16 grid cells that are crossed by the straight line from $x=0$ to $x=x_{\max }$, Fig. 1 .

${ }^{11}$ Precipitation data taken from the gridded monthly precipitation data bank Carbon Cycle Model Linkage-CCMLP (McGuire et al., 2001), time period 1950-1995, grid size $0.5 \times 0.5$ degrees; statistics is based on $P$ values for 20 grid cells that are crossed by the straight line from $x=0$ to $x=x_{\max }$, Fig. 1 .

the year (Hodnett et al., 1996), is limited by the incoming solar energy only. It increases during the dry season when the clear sky conditions predominate (da Rocha et al., 2004; Werth and Avissar, 2004). Dry periods during the veg- etative season in natural forests of higher latitudes neither bring about a decrease of transpiration (Goulden et al., 1997; Tchebakova et al., 2002). In contrast, transpiration of open ecosystems like savannas, grasslands or shrublands incapable 
of maintaining high soil moisture content year round, drops radically during the dry season (Hutley et al., 2001; Kurc and Small, 2004).

Change of soil moisture content with time, $d W / d t$, is linked to precipitation $P$, evaporation $E$ and runoff $R$ via the law of matter conservation, $d W / d t=P-E-R$. In the stationary state after averaging over the year $d W / d t=0$ and runoff $R$ is a function of $W$. Therefore, high amount of soil moisture implies significant runoff, i.e. loss of water by the ecosystem. In areas where neither the surface slope, nor soil moisture content depend on distance $x$ from the ocean, $W(x)=W(0)$, loss of ecosystem water to runoff is spatially uniform as well, $R(x)=R(0)$.

When the soil moisture content is sufficiently high, transpiration is dictated by solar energy. Interception, both from the canopy, understorey and the forest floor, which can be more than $50 \%$ of the total evaporation (Savenije, 2004), is also dictated by solar energy. So if there is sufficient soil moisture, then total evaporation from dense forest is constrained by solar radiation. Therefore, when $x$ is counted along the parallel, on well-moistened continental areas we have $E(x)=E(0)$, i.e. evaporation should not depend on the distance from the ocean. Coupled with constant runoff, $R(x)=R(0)$, this means that precipitation $P$ should similarly be independent of the distance from the ocean, $P(x)=E(0)+R(0)=P(0)$. When the considered area is oriented, and $x$ counted, along the meridian, evaporation increases towards the equator following the increasing flux of solar energy. In such areas, provided soil moisture content and runoff are distance-independent, precipitation must also grow towards the equator irrespective of the distance from the ocean. The conditions $W(x)=W(0)$ and $R(x)=R(0)$ are incompatible with an exponential decline of $P(x)$.

We collected precipitation data for three extensive terrestrial regions spreading along 2.5 thousand kilometers in length each and representing the largest remnants of Earth's natural forest cover (Bryant et al., 1997). These are the Amazon basin, the Congo basin (its equatorial part) and the Yenisey basin, regions 6,7 and 8 in Fig. 1. As can be seen from Fig. 2b, precipitation in the Amazon and Congo basins is independent of the distance from the coast at around $2000 \mathrm{~mm}$ year $^{-1}$. In the Yenisey river basin, which has a meridional orientation, Fig. 1, precipitation increases with distance from the ocean from about $400 \mathrm{~mm} \mathrm{year}^{-1}$ at the mouth to about $800 \mathrm{~mm}$ year ${ }^{-1}$ on the upper reaches of the river, Fig. 2b.

Similar precipitation, $P(0)=790 \mathrm{~mm}$ year $^{-1}$, is registered at $125^{\circ} \mathrm{E}$ in that part of the North East China Continental Transect (NECT) (region 2), which is closest to the Pacific Ocean, $400 \mathrm{~km}$ from the coast. In the meantime, the upper reaches of Yenisey river are about four thousand kilometers away from the Pacific Ocean, and about six thousand kilometers away from the Atlantic Ocean; in fact, it is one of the innermost continental areas on the planet, Fig. 1. Due to the low oceanic temperature in the region of their formation,
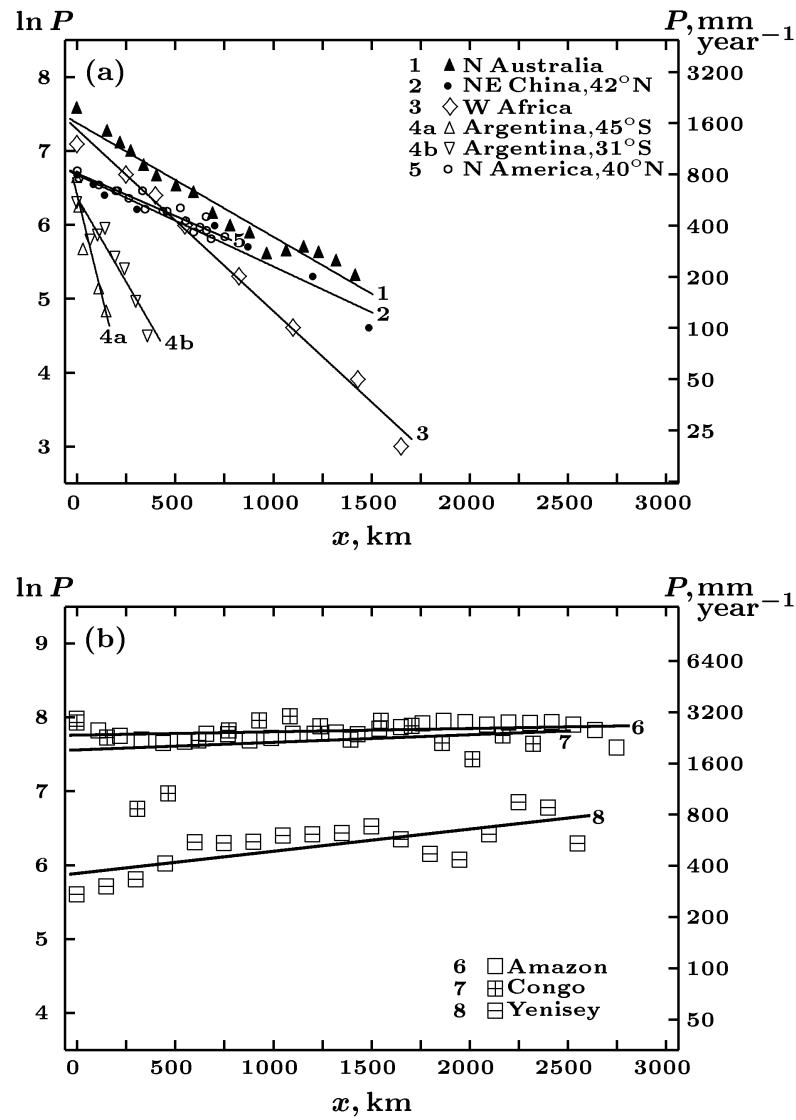

Fig. 2. Dependence of precipitation $P\left(\mathrm{~mm}_{\text {year }}{ }^{-1}\right)$ on distance $x$ $(\mathrm{km})$ from the source of atmospheric moisture on non-forested territories (a) and on territories covered by natural forests (b). Regions are numbered and named as in Table 1 . See Table 1 for parameters of the linear regressions and other details.

Arctic air masses that dominate the Yenisey basin (Shver, 1976) are characterized by low moisture content (less than $8 \mathrm{~mm}$ of precipitable water in the atmospheric column compared to $16 \mathrm{~mm}$ in the Pacific Ocean at NECT (Randel et al., 1996). According to Eq. (1), this moisture content should decrease even further as these air masses move inland to the south.

In other words, if the modern territory of the forestcovered Yenisey basin were, instead, a desert with precipitation of the order of $100 \mathrm{~mm}_{\text {year }}{ }^{-1}$, this would not be surprising from the geophysical point of view (indeed, one is not surprised at the fact that the innermost part of NECT and other non-forested regions, Fig. 2a, are extremely arid). This could easily be explained by the character of atmospheric circulation and large distance from any of the oceans. In contrast, the existence of a luxurious water cycle (Yenisey is the seventh most powerful river in the world) as well as the southward increase of precipitation in this area is quite remarkable, geophysically unexpected and can only be explained by functioning of an active biotic mechanism 
pumping atmospheric moisture from ocean to land. Similar biotic pumps should ensure high precipitation rates throughout the natural forests of the Amazon basin and Equatorial Africa.

It can be concluded, therefore, that all the largest and most powerful river basins must have formed as an outcome of the existence of forest pumps of atmospheric moisture. Forest moisture pump ensures an ocean-to-land flux of moisture, which compensates for the runoff of water from the optimally moistened forest soil. This makes it possible for forests to develop the maximally possible evaporation fluxes that are limited by solar radiation only. Thus, precipitation over forests increases up to the maximum value possible at a given constant runoff (i.e., multiplier $k$ in Eq. (2), the precipitation/runoff ratio, is maximized for a given $R$.) Forest moisture pump determines both the ultimate distance to which the atmospheric moisture penetrates on the continent from the ocean, as well as the magnitude of the incoming moisture flux per unit length of the coastal line. Dictated by the biota, both parameters are practically independent of the geophysical fluctuations of atmospheric moisture circulation. The biotic pumps of atmospheric moisture enhance precipitation on land at the expense of decreasing precipitation over the ocean. This should lead to the appearance of extensive oceanic "deserts" - large areas with low precipitation (see, e.g., Fig. 1 of Adler et al., 2001).

\subsection{Deforestation consequences for the water cycle on land}

Let us denote as $P_{\mathrm{f}}(x)=P_{\mathrm{f}}(0)$ the spatially uniform distribution of precipitation over a river basin covered by natural forest (low index $f$ stands for forest), which spreads over distance $L$ inland and over distance $D$ along the oceanic coast. Total precipitation $\Pi_{\mathrm{f}}$ on this territory is equal to $\Pi_{\mathrm{f}}=P_{\mathrm{f}}(0) L D$, where the product $L D=S$ estimates the area occupied by the river basin. According to Eq. (4) and the results of Sect. 2.1, total precipitation $\Pi_{d}$ on a territory of the same area $S$ deprived of the natural forest cover (low index $\mathrm{d}$ stands for deforestation, desertification) is equal to $\Pi_{\mathrm{d}}=P_{\mathrm{d}}(0) l_{\mathrm{d}} D$, where $l_{\mathrm{d}} \sim 600 \mathrm{~km}$. One thus obtains

$$
\frac{\Pi_{\mathrm{f}}}{\Pi_{\mathrm{d}}}=\frac{P_{\mathrm{f}}(0) L}{P_{\mathrm{d}}(0) l_{\mathrm{d}}}
$$

Equation (5) shows that the deforestation-induced decrease in the mean regional precipitation $\bar{P} \equiv \Pi / S$ in a river basin of linear size $L$ is proportional to $L$. For example, for the Amazon river basin $L \approx 3 \times 10^{3} \mathrm{~km}$, which means that Amazonian deforestation would have led to at least a $L / l_{\mathrm{d}} \approx 5$ fold decrease of mean precipitation in the region. This effect, i.e. a $80 \%$ reduction in precipitation, is several times larger than the available estimates that are based on global circulation models not accounting for the proposed biotic moisture pump. According to such model estimates, deforestation of the Amazon river basin would have led to $\left(\Pi_{\mathrm{f}}-\Pi_{\mathrm{d}}\right) / S=270 \pm 60 \mathrm{~mm}$ year $^{-1}( \pm 1$ s.e., $n=22$ models $)$
(McGuffie and Henderson-Sellers, 2001), i.e. only 13\% of the modern basin mean precipitation of $2100 \mathrm{~mm} \mathrm{year}^{-1}$ (Marengo, 2004).

Reduction of the characteristic distance of the inland propagation of atmospheric moisture from $L$ to $l_{\mathrm{d}} \ll L$ is not the single consequence of deforestation. Impairment of the biotic moisture pump in the course of deforestation causes the ocean-to-land flux of atmospheric moisture via the coastal zone to diminish. In the result, the amount of precipitation $P(0)$ in the coastal zone decrease from the initial high biotic value $P(0)=P_{\mathrm{f}}(0)$ down to $P(0)=P_{\mathrm{d}}(0)<P_{\mathrm{f}}(0)$. As will be shown in Sect. 3.3, in the case of complete elimination of the vegetation cover, precipitation in the coastal zone can be reduced practically to zero, $P_{\mathrm{d}}(0)=0$, see Fig. $4 \mathrm{a}$. In the case when the natural forest is replaced by an open-canopy, low leaf area index ecosystem, cf. Fig. 4b,c in Sect. 3.3, the characteristic magnitude of reduction in $P(0)$ can be estimated comparing the observed values of precipitation $P(0)$ in the coastal zones of forested versus non-forested territories under similar geophysical conditions of atmospheric circulation. A good example is the comparison of the arid ecosystem in the northeast Brazil, the so-called caatinga, which receives about $P_{\mathrm{d}}(0)=800 \mathrm{~mm}$ year ${ }^{-1}$ precipitation (Oyama and Nobre, 2004), with the forested coast of the Amazon river basin, where $P_{\mathrm{f}}(0)>2000 \mathrm{~mm}_{\mathrm{f}} \mathrm{ear}^{-1}$ (Marengo, 2004), which gives $P_{\mathrm{f}}(0) / P_{\mathrm{d}}(0)>2.5$. According to Eq. (5), the cumulative effect of deforestation can amount to more than a tenfold reduction of the mean basin precipitation. The innermost continental areas will be most affected. For example, at $x=1200 \mathrm{~km}$ (in the Amazon river basin this approximately corresponds to the city of Manaus, Brazil) local precipitation will decrease by

$$
\frac{P_{\mathrm{f}}(x)}{P_{\mathrm{d}}(x)}=\frac{P_{\mathrm{f}}(0)}{P_{\mathrm{d}}(0)} \frac{1}{\exp (-x / l)}=\frac{2.5}{\exp (-1200 / 600)}=19
$$

times, while in Rio Branco, Brazil $(x \approx+2500 \mathrm{~km})$ precipitation will decrease by 160 times, i.e. the internal part of the continent will turn to a desert. Total river runoff from the basin to the ocean, which is equal to $\int_{0}^{L} R(x) d x=\Pi / k$, see Eq. (2), will undergo the same or even more drastic changes as the total precipitation, Eq. (5), due to increase of multiplier $k$ in deserts, Eq. (2).

Ratio $\Pi_{f} / \Pi_{d}>10$, Eq. (5), characterizes the power of the biotic pump of atmospheric moisture: the biotically induced ocean-to-land moisture flux does not decrease exponentially with distance from the ocean and it is more than an order of magnitude larger than in the biotically non-controlled state. At any distance from the ocean and under any fluctuations of the external geophysical conditions this moisture flux prevents forest soil from drying. As follows from the above ratio, geophysical fluctuations of the precipitation regime can be no more than $10 \%$ as powerful as the biotic pump. Relative fluctuations of river runoff are dictated by fluctuations in the work of the biotic pump, i.e. they do not exceed $10 \%$ 
of its power either. This prevents floods in the forested river basin.

In the theoretical consideration of moisture recycling (Savenije, 1996b) precipitation $P$ is ultimately related to the horizontal flux of moisture, which is considered as an abiotic geophysical constraint, an independent parameter; evaporation $E$ is known to be affected by vegetation; and runoff $R$ is the residual of $P$ and $E$. This consideration, where both $P$ and $R$ can be arbitrarily high or low, corresponding to either droughts and floods, should hold well for non-forested regions like deserts, agricultural lands etc.

In the biotic pump consideration a different meaning is assigned to the budget $P=E+R$. In the biotically controlled forest environment runoff $R$ is determined by the biotically maintained high soil moisture, total evaporation $E$ is dictated by solar energy, and precipitation $P$ is biotically regulated (via the biotically regulated flux $F$ ) to balance the equation. In this consideration it is clear that, as is also confirmed by observations, in natural forests neither floods nor disastrous diminishment of runoff can normally occur throughout the year. Summing up, the undisturbed natural forests create an autonomous cycle of water on land, which is decoupled from whatever abiotic environmental fluctuations. We will now consider the physical and biological principles along which this unique biotic mechanism functions.

\section{Physical foundations of the biotic pump of atmo- spheric moisture}

3.1 Aerostatic equilibrium, hydrostatic equilibrium and the non-equilibrium vertical distribution of atmospheric water vapor

In this section we describe a physical effect, which, as we show, plays an important role in the meteorological processes on Earth, but so far remains practically undiscussed in the meteorological literature.

Aerostatic equilibrium of a gas mixture like moist air means that change $d p_{i}$ of partial pressure $p_{i}$ of the $i$-th gas over vertical distance $d z$ is balanced by the weight of this gas in the atmospheric layer of thickness $d z$ (Landau and Lifschitz, 1987):

$-\frac{d p_{i}}{d z}=\rho_{i} g$.

If each gas in the mixture obeys Eq. (7), for the mixture as a whole one has

$$
\begin{aligned}
-\frac{d p}{d z} & =\rho g ; \\
p & =\sum p_{i}, \quad \rho=\sum \rho_{i}=\sum N_{i} M_{i} .
\end{aligned}
$$

Here $\rho_{i}\left(\mathrm{~g} \mathrm{~m}^{-3}\right)$ and $N_{i}\left(\mathrm{~mol} \mathrm{~m}^{-3}\right)$ are mass density and molar density of the $i$-th gas at height $z, M_{i}\left(\mathrm{~g} \mathrm{~mol}^{-1}\right)$ is its molar mass, $g=9.8 \mathrm{~m} \mathrm{~s}^{-2}$ is the acceleration of gravity; $p$ and $\rho$ are pressure and mass density of moist air as a whole, respectively. Equation (8) can be written for gases as well as liquids and is often called the equation of hydrostatic equilibrium. It should be stressed that while the fulfillment of Eq. (7) for each mixture constituent guarantees the fulfillment of Eq. (8) for mixture as a whole, the opposite is not true.

Atmospheric gases are close to ideal and conform to the equation of state for ideal gas:

$$
\begin{array}{r}
p_{i}=N_{i} R T \equiv \rho_{i} g h_{i}, h_{i} \equiv \frac{R T}{M_{i} g}, \\
p=N R T \equiv \rho g h, h \equiv \frac{R T}{M g}, \\
N=\sum N_{i}, M \equiv \rho / N,
\end{array}
$$

where $T$ is absolute air temperature at height $z, R=8.3 \mathrm{~J} \mathrm{~K}^{-1}$ $\mathrm{mol}^{-1}$ is the universal gas constant. Therefore, Eq. (7) and its solution can be written in the following well-known form (Landau and Lifschitz, 1987; McEwan and Phillips, 1975):

$\frac{d p_{i}}{d z}=-\frac{p_{i}}{h_{i}}, \quad p_{i}(z)=p_{i s} \exp \left\{-\int_{0}^{z} \frac{d z}{h_{i}}\right\}$,

where $p_{i s}$ is partial pressure of the $i$-th gas at the Earth's surface.

Aerostatic equilibrium of the gas mixture as a whole cannot be written in the form of a single differential equation with exponential solution (10), as far as functions $N$ (9) and $\rho$ (8) depend in different ways on molar concentrations $N_{i}$. In the troposphere, according to observations (see, e.g., McEwan and Phillips, 1975), gases of dry air have one and the same vertical distribution with molar mass $M_{d}=29$ $\mathrm{g} \mathrm{mol}^{-1}$ independent of height $z$. As far as $p_{d} / h_{d}=\rho_{d} g$, $h_{d} \equiv R T /\left(M_{d} g\right), h_{d s}=8.4 \mathrm{~km}$, see Eq. (9), dry air obeys Eq. (8) for hydrostatic equilibrium (if it is written for $p_{d}$ and $\rho_{d}$ instead of $p$ and $\rho$ ). But dry air is not in aerostatic equilibrium; vertical distribution of each particular $i$-th dry air constituent does not conform to Eqs. (7) and (10), eventhough vertical distribution of dry air as a whole (low index $d$ ) formally obeys Eqs. (10) at $i=d$. Moist air does not conform to either Eq. (7) or Eq. (8).

Aerostatic equilibrium of atmospheric water vapor (low index $v$ ) with molar mass $M_{v}=18 \mathrm{~g} \mathrm{~mol}^{-1}$ is described by Eq. (10) with $i=v$ and $h_{i}$ replaced by $h_{v} \equiv R T / M_{v} g$, $h_{v s} \equiv R T_{s} / M_{v} g=13.5 \mathrm{~km}$.

Immediately above wet soil or open water surface, water vapor is in the state of saturation. The dependence of partial pressure $p_{\mathrm{H}_{2} \mathrm{O}}$ of saturated water vapor on air temperature $T$ is governed by the well-known Clapeyron-Clausius law (Landau et al., 1965):

$$
\begin{gathered}
\frac{d p_{\mathrm{H}_{2} \mathrm{O}}}{d z}=-\frac{p_{\mathrm{H}_{2} \mathrm{O}}}{h_{\mathrm{H}_{2} \mathrm{O}}}, \quad p_{\mathrm{H}_{2} \mathrm{O}}=p_{\mathrm{H}_{2} \mathrm{O} s} \exp \left\{-\int_{0}^{z} \frac{d z}{h_{\mathrm{H}_{2} \mathrm{O}}}\right\}, \\
h_{\mathrm{H}_{2} \mathrm{O}} \equiv \frac{T^{2}}{\left\{-\frac{d T}{d z}\right\} T_{\mathrm{H}_{2} \mathrm{O}}}, \quad T_{\mathrm{H}_{2} \mathrm{O}} \equiv \frac{Q_{\mathrm{H}_{2} \mathrm{O}}}{R} \approx 5300 \mathrm{~K},
\end{gathered}
$$


where, as everywhere else, low index $s$ refers to corresponding values at the Earth's surface, $Q_{\mathrm{H}_{2} \mathrm{O}} \approx 44 \mathrm{~kJ} \mathrm{~mol}^{-1}$ is the molar latent heat of evaporization.

Equations (11) have the same form as the aerostatic equilibrium equations (10), but with a different height parameter $h_{\mathrm{H}_{2} \mathrm{O}}$, which, in the case of water vapor, depends on the atmospheric lapse rate $\Gamma$ of air temperature, $\Gamma \equiv-d T / d z$.

Written for water vapor with $h_{v}$ instead of $h_{i}$, Eqs. (10) formally coincide with Eqs. (11) if the equality $h_{\mathrm{H}_{2} \mathrm{O}}=h_{v}$ is fulfilled. This equality can be solved for the atmospheric temperature lapse rate $\Gamma$. The obtained solution $\Gamma=\Gamma_{\mathrm{H}_{2} \mathrm{O}}$ corresponds to the case when water vapor is saturated in the entire atmospheric column and at the same time is in aerostatic equilibrium, i.e. at any height $z$ its partial pressure is equal to the weight of water vapor in the atmospheric column above $z$. Equating the scale heights $h_{v} \equiv R T / M_{v} g$, Eq. (10) and $h_{\mathrm{H}_{2} \mathrm{O}}$, Eq. (11), we arrive at the following value of $\Gamma_{\mathrm{H}_{2} \mathrm{O}}$ :

$$
\begin{array}{r}
-\frac{d T}{d z}=\frac{T}{H}, \quad T=T_{s} e^{-z / H}, \\
-\frac{d T}{d z} \equiv \Gamma_{\mathrm{H}_{2} \mathrm{O}}=\frac{T_{s}}{H}=1.2 \mathrm{~K} \mathrm{~km}^{-1}, \\
H \equiv \frac{R T_{\mathrm{H}_{2} \mathrm{O}}}{M_{v} g}=250 \mathrm{~km} .
\end{array}
$$

Note that due to the large value of $H \gg h_{v}, h_{v} / H \approx 0.05 \ll 1$, one can put $\exp (-z / H) \approx 1$ for any $z \leq h_{v}$, which we did when obtaining Eq. (12). In Eq. (12) $\Gamma_{\mathrm{H}_{2} \mathrm{O}}=1.2 \mathrm{~K} \mathrm{~km}^{-1}$ is calculated for the mean global surface temperature $T_{s}=288 \mathrm{~K}$. Differences in the absolute surface temperatures of equatorial and polar regions change this value by no more than $10 \%$.

The obtained value of $\Gamma_{\mathrm{H}_{2} \mathrm{O}}=1.2 \mathrm{~K} \mathrm{~km}^{-1}$, Eq. (12), is a fundamental parameter dictating the character of atmospheric processes.

When $\Gamma<\Gamma_{\mathrm{H}_{2} \mathrm{O}}$, water vapor in the entire atmosphere is in aerostatic equilibrium, but it is saturated at the surface only, i.e. $p_{v}(z)<p_{\mathrm{H}_{2} \mathrm{O}}(T(z))$ for $z>0$ and $p_{v}(z)=p_{\mathrm{H}_{2} \mathrm{O}}\left(T_{s}\right)$ for $z=0$, where $p_{v}$ is partial pressure of water vapor at height $z$ (and $p_{\mathrm{H}_{2} \mathrm{O}}$, as before, is the saturated pressure of water vapor at $T(z))$. Relative humidity $p_{v} / p_{\mathrm{H}_{2} \mathrm{O}}$ decreases with height. As far as in the state of aerostatic equilibrium water vapor partial pressure $p_{v}$, as well as partial pressures $p_{i}$ of other air gases, at a given height $z$ are compensated by the weight of these gases and water vapor in the atmospheric column above $z$, in this state macroscopic fluxes of air and water vapor in the atmosphere are absent. Evaporation and precipitation are zero at any surface temperature. Solar radiation absorbed by the Earth's surface makes water evaporate from the oceanic and soil surface, but the evaporated water undergoes condensation at a microscopic distance above the surface, which is of the order of one free path length of water vapor molecules. Energy used for evaporation is ultimately released in the form of thermal radiation of the Earth's surface, with no input of latent heat into the atmosphere.
At $\Gamma>\Gamma_{\mathrm{H}_{2} \mathrm{O}}$ the situation is quite different. In this case atmospheric water vapor cannot be in aerostatic equilibrium, Eq. (7), in that part of the atmospheric column where it is saturated, i.e. where $p_{v}(z)=p_{\mathrm{H}_{2} \mathrm{O}}(T(z))$. Due to the steep decline of air temperature with height, the atmospheric column above $z$ cannot bear a sufficient amount of water vapor for its weight to compensate saturated water vapor partial pressure at height $z$. The excessive moisture condenses and precipitates. The lapse rate of water vapor partial pressure, $-d p_{v} / d z$, is larger than the weight of a unit volume of saturated water vapor, Eq. (7). There appears an uncompensated force acting on atmospheric air and water vapor. Under this force, upward fluxes of air and water vapor originate that are accompanied by the vertical transport of latent heat. With water vapor continuously leaving the surface layer for the upper atmosphere, saturation of water vapor near the surface can be maintained by continuous evaporation and advective (horizontal) inputs of water vapor. In the imaginary case when evaporation discontinues, all atmospheric water vapor ultimately condenses and the stationary global partial pressure of atmospheric water vapor will be zero. In contrast, at $\Gamma<\Gamma_{\mathrm{H}_{2} \mathrm{O}}$ any surface value of water vapor partial pressure $p_{v s} \leq p_{\mathrm{H}_{2} \mathrm{O}}\left(T_{s}\right)$ can be stationarily maintained in the absence of evaporation.

Violation of aerostatic equilibrium is manifested as a strong compression of the vertical distribution of water vapor as compared to the distribution of dry atmospheric air, Eq. (10) for $i=d$ ( $d$ stands for dry air). At the observed mean atmospheric value of $\Gamma=\Gamma_{o b}=6.5 \mathrm{~K} \mathrm{~km}^{-1}$, see Appendix A, we obtain from Eqs. (10), (11) and (12):

$\frac{h_{d}}{h_{\mathrm{H}_{2} \mathrm{O}}}=\frac{\Gamma_{o b}}{\Gamma_{\mathrm{H}_{2} \mathrm{O}}} \frac{M_{v}}{M_{d}} \frac{T_{s}}{T} \equiv \beta \equiv \beta_{s} \frac{T_{s}}{T}, \beta_{s}=3.5$.

The compression coefficient $\beta$ grows weakly with $z$ due to the $z$-dependent drop of temperature $T$ corresponding to $\Gamma_{o b}=6.5 \mathrm{~K} \mathrm{~km}^{-1}$. At $z=h_{\mathrm{H}_{2} \mathrm{O}}$, which defines the characteristic vertical scale of water vapor distribution, $\beta$ increases by $5 \%$ compared to its value at the surface $\beta_{s}$. Ignoring this change and putting $\beta$ constant at $\beta=\beta_{s}$ we obtain from Eqs. (10), (11), and (13):

$$
\begin{aligned}
& \quad \frac{p_{\mathrm{H}_{2} \mathrm{O}}(z)}{p_{\mathrm{H}_{2} \mathrm{O} s}}=\exp \left\{-\int_{0}^{z} \frac{d z}{h_{\mathrm{H}_{2} \mathrm{O}}}\right\}= \\
& =\exp \left\{-\int_{0}^{z} \beta \frac{d z}{h_{d}}\right\} \approx\left\{\frac{p_{d}(z)}{p_{d s}}\right\}^{\beta} .
\end{aligned}
$$

Equation (14) shows that the vertical distribution of water vapor in the troposphere is compressed 3.5-fold as compared to the vertical distribution of atmospheric air. Its scale height $h_{\mathrm{H}_{2} \mathrm{Os}}$ is calculated as $h_{\mathrm{H}_{2} \mathrm{O} s}=h_{s} / \beta_{s}=2.4 \mathrm{~km}$. This theoretical calculation agrees with the observed scale heights $\approx 2 \mathrm{~km}$ of the vertical profiles of atmospheric water vapor (Goody and Yung, 1989; Weaver and Ramanathan, 1995).

Let us now emphasize the difference between the physical picture that we have just described and the traditional consideration of atmospheric motions. The latter resides on the 
notion of convective instability of the atmosphere associated with the adiabatic lapse rate $\Gamma_{a}$ (dry or wet). If an air parcel is occasionally heated more than the surrounding air, it acquires a positive buoyancy and, under the Archimedes force, can start an upward motion in the atmosphere. In such a case its temperature decreases with height $z$ at a rate $\Gamma_{a}$. If the environmental lapse rate $\Gamma$ is steeper than $\Gamma_{a}, \Gamma>\Gamma_{a}$, the rising parcel will always remain warmer and lighter that the surrounding air, thus infinitely continuing its ascent. Similar reasoning accompanies the picture of a descending air parcel initially cooled to a temperature lower than that of the surrounding air. On such grounds, it is impossible to determine either the degree of non-uniformity of surface heating responsible for the origin of convection, or the direction or velocity of the resulting movement of air masses. After averaging over a horizontal scale exceeding the characteristic height $h$ of the atmosphere, mean Archimedes force turns to zero. This means that the total air volume above an area greatly exceeding $h^{2}$ cannot be caused to move anywhere by the Archimedes force.

According to the physical laws that we have discussed, upward fluxes of air and water vapor always arise when the environmental lapse rate exceeds $\Gamma_{\mathrm{H}_{2} \mathrm{O}}=1.2 \mathrm{~K} \mathrm{~km}^{-1}$. This critical value is significantly lower than either dry or wet adiabatic lapse rates $\Gamma_{a}$ (9.8 and $\approx 6 \mathrm{~K} \mathrm{~km}^{-1}$, respectively). The physical cause of these fluxes is not the non-uniformity of atmospheric and surface heating, but the fact that water vapor is not in aerostatic equilibrium and its partial pressure is not compensated by its weight in the atmospheric column, Fig. 3a. The resulting force is invariably upward-directed, Fig. 3b. It equally acts on air volumes with positive and negative buoyancy, in agreement with the observation that atmospheric air updrafts exhibit a wide range of both positive and negative buoyancies (Folkins, 2006). Quantitative consideration of this force, which creates upwelling air and water vapor fluxes and supports clouds over large areas of the Earth's surface, makes it possible to estimate characteristic velocities of the vertical and horizontal motions in the atmosphere, which is done in the next sections.

\subsection{Vertical fluxes of atmospheric moisture and air}

The Euler equation for the stationary vertical motion of moist air under the force $f_{E}$ generated by the non-equilibrium pressure gradient of atmospheric water vapor can be written as follows (Landau and Lifschitz, 1987):

$\frac{1}{2} \rho \frac{d w^{2}}{d z}=-\frac{d p}{d z}-\rho g=-\frac{d p_{v}}{d z}-\rho_{v} g \equiv f_{E}$

Here $\rho=\rho_{d}+\rho_{v}$ and $p=p_{d}+p_{v}$ are density and pressure of moist air at height $z$, respectively; $\rho_{d}, \rho_{v}$ and $p_{d}, p_{v}$ are density and pressure of dry air and water vapor at height $z$, respectively; $w$ is vertical velocity of moist air at height $z$; it is taken into account that dry air is in hydrostatic equilibrium, i.e. $-d p_{d} / d z-\rho_{d} g=0$.
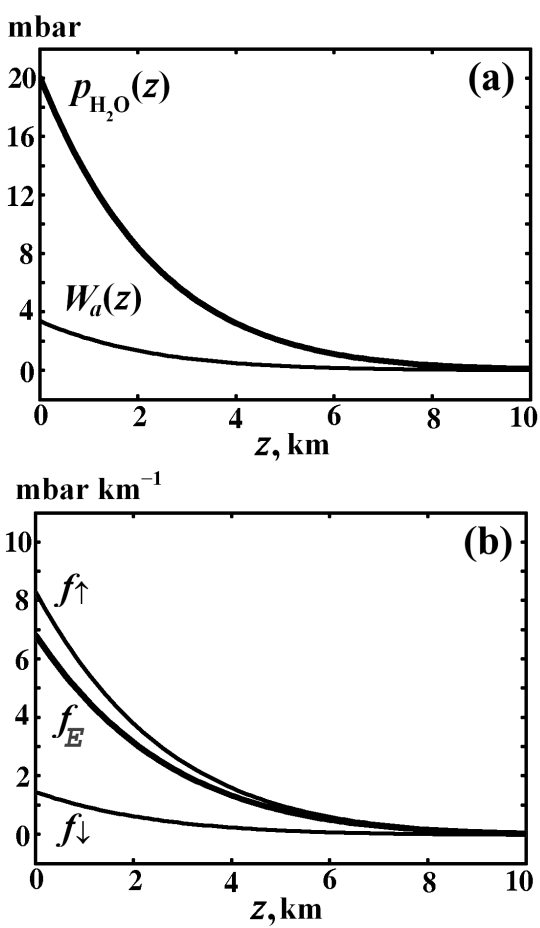

Fig. 3. Water vapor partial pressure and evaporative force in the terrestrial atmosphere. (a) Saturated partial pressure of water vapor $p_{\mathrm{H}_{2} \mathrm{O}}(z)$, Eq. (11), and weight of the saturated water vapor $W_{a}(z) \equiv \int_{z}^{\infty} \frac{p_{\mathrm{H}_{2} \mathrm{O}}\left(z^{\prime}\right)}{h_{v}(z)^{\prime}} d z^{\prime}$ in the atmospheric column above height $z$ at $\Gamma_{o b}=6.5 \mathrm{~K} \mathrm{~km}^{-1}$. Saturated partial pressure at the surface is $p_{\mathrm{H}_{2} \mathrm{O}}(0)=20$ mbar. (b) The upward-directed evaporative force $f_{E}$, Eq. (16), equal to the difference between the upward directed pressure gradient force $f_{\uparrow}(z)$ and the downward directed weight $f_{\downarrow}$ of a unit volume of the saturated water vapor, $f_{E}=f_{\uparrow}-f_{\downarrow}$.

For saturated water vapor, $p_{v}=p_{\mathrm{H}_{2} \mathrm{O}}$, under conditions of the observed atmospheric lapse rate $\Gamma_{o b}=6.5 \mathrm{~K} \mathrm{~km}^{-1}$, when $p_{\mathrm{H}_{2} \mathrm{O}}$ is given by Eq. (11), we have from Eq. (15):

$$
\begin{array}{r}
f_{E}=-\frac{d p_{\mathrm{H}_{2} \mathrm{O}}}{d z}-\frac{p_{\mathrm{H}_{2} \mathrm{O}}}{h_{v}}=p_{\mathrm{H}_{2} \mathrm{O}}\left(\frac{1}{h_{\mathrm{H}_{2} \mathrm{O}}}-\frac{1}{h_{v}}\right)= \\
=\left(\beta-\beta_{v}\right) \rho \gamma g .
\end{array}
$$

Here $\beta_{v} \equiv M_{v} / M \approx 0.62, \beta$ is given by Eq. (13), $\gamma \equiv p_{\mathrm{H}_{2} \mathrm{O}} / p$ is mixing ratio of saturated water vapor; $h_{v}=R T / M_{v} g$. Since $\gamma \ll 1$, we put with a very good accuracy $M=M_{d}$, $\rho=\rho_{d}$.

Force $f_{E}$, Eq. (16), acting on a unit moist air volume is equal to the difference between the upward directed pressure gradient force $f_{\uparrow}(z)$ associated with partial pressure of the vertically compressed saturated water vapor, $f_{\uparrow}(z) \equiv-d p_{\mathrm{H}_{2} \mathrm{O}}(z) / d z=p_{\mathrm{H}_{2} \mathrm{O}} / h_{\mathrm{H}_{2} \mathrm{O}}$, and the downward directed weight $f_{\downarrow}$ of a unit volume of the saturated water vapor, $f_{\downarrow} \equiv p_{\mathrm{H}_{2} \mathrm{O}}(z) / h_{v}: f_{E}=f_{\uparrow}-f_{\downarrow}$, Fig. $3 \mathrm{~b}$. Due to the vertical compression of water vapor as compared to the state of hydrostatic equilibrium of dry air, at any height $z$ the pressure 
of moist air, $p=p_{d}+p_{\mathrm{H}_{2} \mathrm{O}}$, becomes larger than the weight of the atmospheric column above $z$, so force $f_{E}$ arises. Acted upon by this upward directed force at any height $z$, volumes of moist air start to rise tending to compensate the insufficient weight of the atmospheric column above $z$.

As can be seen from Eq. (16), force $f_{E}$ is proportional to the local concentration $N_{\mathrm{H}_{2} \mathrm{O}}=p_{\mathrm{H}_{2} \mathrm{O}} / R T$ of the saturated water vapor. As far as the ascending water vapor molecules undergo condensation, the stationary existence of force $f_{E}$ is only possible in the presence of continuous evaporation from the surface, which would compensate for the condensation. It is therefore natural to term force $f_{E}$, Eq. (16), as the evaporative force.

As is well-known, the horizontal barometric gradient force accelerates air masses up to certain velocities when the relevant Coriolis force caused by Earth's rotation comes into play. It grows proportionally to velocity and is perpendicular to the velocity vector. These two forces along with the centrifugal force of local rotational movements, the turbulent friction force describing the decay of large air eddies into smaller ones, and the laws of momentum and angular momentum conservation together explain the observed atmospheric circulation patterns like gradient winds in cyclones and anticyclones, cyclostrophic winds in typhoons and tornadoes, as well as geostrophic winds in the upper atmosphere where turbulent friction is negligible. However, the origin, magnitude and spatial distribution of the horizontal barometric gradient - the primary cause of atmospheric circulation - has not so far received a satisfactory explanation (Lorenz, 1967). Below we show that the observed values of the barometric gradient are determined by the magnitude of the evaporative force. The various patterns of atmospheric circulation correspond to particular spatial and temporal changes in the fluxes of evaporation, so the evaporative force drives the global atmospheric circulation.

In agreement with Dalton's law, partial pressures of different gases in a mixture independently come in or out of the equilibrium. The non-equilibrium state of atmospheric water vapor cannot bring about a compensating deviation from the equilibrium of the other air gases, to zero the evaporative force. (In such a hypothetical case the vertical distribution of air would be "overstretched" along the vertical, in contrast to the distribution of water vapor which is vertically compressed as compared to the state of aerostatic equilibrium.) A non-equilibrium vertical distribution of air concentration would initiate downward diffusional fluxes of air molecules working to restore the equilibrium. As soon as air molecules undergo a downward diffusional displacement, the weight of the upper atmospheric column diminishes rendering partial pressure of the water vapor uncompensated, and the evaporative force reappears. (A similar effect when a fluid-moving force arises in the course of diffusion of fluid mixtures with initially non-equilibrium concentrations is inherent to the phenomenon of osmosis.) Thus, the only possible stationary state in the case of non-equilibrium vertical distribution of water vapor, Eq. (14), is the dynamic state when parcels of moist air move under the action of the evaporative force. According to the law of matter conservation, movement trajectories should be closed for air molecules and partially closed (taking into account condensation and precipitation of moisture) for the water vapor. The particular shape of these trajectories will be dictated by the boundary conditions.

Flux of $\mathrm{H}_{2} \mathrm{O}$ molecules through the liquid-gas interface is determined by temperature only. At fixed temperature it is the same at $\Gamma \leq \Gamma_{\mathrm{H}_{2} \mathrm{O}}$ and $\Gamma>\Gamma_{\mathrm{H}_{2} \mathrm{O}}$. At $\Gamma \leq \Gamma_{\mathrm{H}_{2} \mathrm{O}}$ the evaporative force is equal to zero; evaporation, i.e. flux of water vapor from the liquid water surface to the macroscopic atmospheric layers, is absent; the temperature-dictated flux of $\mathrm{H}_{2} \mathrm{O}$ molecules from liquid to gas is compensated by the reverse flux of molecules from gas to liquid at a microscopic distance from the surface. At $\Gamma>\Gamma_{\mathrm{H}_{2} \mathrm{O}}$ the evaporative force is not zero; it "sucks" water vapor (and air) up to the atmosphere from the microscopic layer at the surface; there appears a non-zero evaporation. The evaporative force accelerates moist air until the dynamic upward flux of water vapor $w N_{\mathrm{H}_{2} \mathrm{O}}$ becomes equal to the stationary evaporation flux $E$ determined by solar radiation. After this value is reached at a certain (quite small) height $z$ in the atmosphere, the acceleration starts to drop very rapidly with height, because local water vapor concentration drops below the saturated value, relative humidity becomes less than unity, water vapor tends to aerostatic equilibrium and the evaporative force drops sharply, Eq. (15). In the result, vertical velocity of moist air can remain practically constant at any height in the atmospheric column. At some height of the order of $h_{\mathrm{H}_{2} \mathrm{O}}$, where water vapor reaches saturation, the evaporative force increases. In the stationary case it compensates for the friction force acting on water droplets appearing in the course of water vapor condensation, thus maintaining clouds at a certain height in the atmosphere, as well as for the friction force acting on the horizontally moving air at the surface.

In the stationary case the dynamic ascending flux of moist air removing $w N_{\mathrm{H}_{2} \mathrm{O}}$ mol water vapor from unit surface area per unit time, where $w$ is vertical velocity, should be compensated by the incoming flux $K$ bringing moisture to the considered area, $K=w N_{\mathrm{H}_{2} \mathrm{O}}$. On the global average, $K$ is fixed by flux $E$ of evaporation from the Earth's surface. For the global mean value of $\bar{E} \approx 10^{3} \mathrm{~kg} \mathrm{H}_{2} \mathrm{O} \mathrm{m}^{-2}$ year $^{-1}$ $\approx 55 \times 10^{3} \mathrm{~mol} \mathrm{~m}^{-2}$ year $^{-1}$ and saturated water vapor concentration at the surface $N_{\mathrm{H}_{2} \mathrm{Os}}=0.7 \mathrm{~mol} \mathrm{~m}^{-3}$ at the global mean surface temperature $T_{S}=288 \mathrm{~K}$ we obtain

$w_{\bar{E}}=\bar{E} / N_{\mathrm{H}_{2} \mathrm{O}}=2.5 \mathrm{~mm} \mathrm{~s}^{-1}$.

If $K$ is determined by evaporation supported by advective heat fluxes or directly by the horizontal advective moisture inputs from the neighboring areas, its value can significantly exceed mean local evaporation $E$. In such a case vertical velocity of moist air movement under the action of the evaporative force can reach its maximum value $w_{\max }$, when the 
evaporative force accelerates air parcels along the entire atmospheric column. Using the expression for air pressure $p \approx p_{d}$ given by Eq. (10) for $i=d$, the approximate equality in Eq. (14), and recalling that $\rho=p / g h$, one can estimate $w_{\max }$ from Eq. (16) as

$$
\begin{array}{r}
w_{\max }=\left[2\left(\beta-\beta_{v}\right) g \gamma_{s} \int_{0}^{\infty} d z \exp \left\{-\int_{0}^{z}(\beta-1) \frac{d z^{\prime}}{h}\right\}\right]^{\frac{1}{2}} \approx \\
\approx \sqrt{2 \gamma_{s} g h_{s}} \approx 50 \mathrm{~m} \mathrm{~s}^{-1} .
\end{array}
$$

where $\gamma_{s} \equiv p_{\mathrm{H}_{2} \mathrm{O} s} / p_{s} \approx 2 \times 10^{2}, h_{s}=8.4 \mathrm{~km}, g=9.8 \mathrm{~m} \mathrm{~s}^{-2}$.

The obtained theoretical estimate Eq. (18) is in good agreement with the maximum updraft velocities observed in typhoons and tornadoes (e.g. Smith, 1997). The value of $w_{\max }$, Eq. (18), exceeds the global mean upward velocity $w_{\bar{E}}$, Eq. (17), which is stationarily maintained by the global mean evaporation $\bar{E}$ at the expense of solar energy absorbed by the Earth's surface, by $\sim 10^{4}$ times. Such velocities can be attained if only there is a horizontal influx of water vapor and heat into the considered local area where the air masses ascend, from an adjacent area which is $\sim 10^{4}$ times larger, i.e. from a distance one hundred of times greater than the characteristic maximum wind radius in tornadoes and hurricanes.

Movement of air masses under the action of the evaporative force follow closed trajectories, which have to include areas of ascending, descending and horizontal motion. The vertical pressure difference $\Delta p_{z}$ associated with the evaporative force is equal to $\Delta p_{z} \approx p_{\mathrm{H}_{2} \mathrm{O}} \sim 10^{-2} p_{s}$, where $p_{s}=10^{5} \mathrm{~Pa}$ is atmospheric pressure at the Earth's surface. The value of $\Delta p_{z}$, about one per cent of standard atmospheric pressure, should give the scale of atmospheric pressure changes at the sea level in cyclones and anticyclones; this agrees well with observations. Given that the scale length $r$ of the areas with consistent barometric gradient does not exceed several thousand kilometers, at $r \sim 10^{3} \mathrm{~km}$ the horizontal barometric gradient is estimated as $\partial p / \partial x \sim \Delta p_{z} / r \sim 1 \mathrm{~Pa} \mathrm{~km}^{-1}$. Again, this theoretical estimate agrees well with characteristic magnitude of horizontal pressure gradients observed on Earth.

Taking into account that movement of air masses under the action of the evaporative force with a mean vertical velocity $w_{\bar{E}}$, Eq. (17), is the cause of the turbulent mixing of the atmosphere, it is also possible to obtain a theoretical estimate of the turbulent diffusion coefficient for the terrestrial atmosphere. If there is a gradient of some variable $C$ in the atmosphere, the diffusion flux $F_{v}$ of this variable is described by the equation of turbulent (eddy) diffusion, $F_{v}=-v\left[\partial C / \partial z-(\partial C / \partial z)_{0}\right]$, where $(\partial C / \partial z)_{0}$ is the equilibrium gradient and the eddy (turbulent) diffusion coefficient $v\left(\mathrm{~m}^{2} \mathrm{~s}^{-1}\right)$ (kinematic viscosity) does not depend on the nature of the variable or its magnitude. This relationship is formally similar to the equation of molecular diffusion. However, molecular diffusion fluxes are caused by concentration gradients alone, with no forces acting on the fluid. Molecular diffusion coefficient is unambiguously determined by the physical properties of state, in particular, by the mean velocity and free path length of air molecules. In contrast, turbulent fluxes are caused by air eddies that are maintained by certain physical forces acting on macroscopic air volumes and making them move; thus, the eddy diffusion coefficient depends on air velocity. Therefore, using the empirically established eddy diffusion coefficient for the determination of the characteristic air velocity via the scale length of the considered problem, a common feature of many theoretical studies of global circulation, e.g., (Fang and Tung, 1999), represents a circular approach. It sheds no light on the physical nature and magnitude of the primary forces responsible for air motions.

As is well-known, eddy diffusion coefficient can be estimated if one knows the characteristic velocity and linear scale of the largest turbulent eddies (Landau and Lifschitz, 1987). Theoretically obtained vertical velocity $w_{\bar{E}}$, Eq. (17), and the scale height $h_{\mathrm{H}_{2} \mathrm{O}} \sim 2 \mathrm{~km}$ of the vertical distribution of atmospheric water vapor make it possible to estimate the global mean atmospheric eddy diffusion coefficient (which, for atmospheric air, coincides with the coefficient of turbulent kinematic viscosity) as $v \sim w_{\bar{E}} h_{\mathrm{H}_{2} \mathrm{O}} \sim 6 \mathrm{~m}^{2} \mathrm{~s}^{-1}$. This estimate agrees in the order of magnitude with, but is about two times greater than, the phenomenological value of $v \sim 3.5$ $\mathrm{m}^{2} \mathrm{~s}^{-1}$ used in global circulation studies (Fang and Tung, 1999).

However, when obtaining the estimate of vertical velocity $w_{\bar{E}}$, Eq. (17), it was assumed that the mean global flux of evaporation $\bar{E}$ is equal to the vertical dynamic flux $F_{w}=w_{\bar{E}} N_{\mathrm{H}_{2} \mathrm{O}}$ of water vapor, $\bar{E}=F_{w}$, while in reality it is equal to the sum of the dynamic $F_{w}$ and eddy $F_{v}$ fluxes of water vapor, $\bar{E}=F_{w}+F_{\nu}$. The upward eddy flux of water vapor is equal to $F_{v}=-v\left[\partial N_{\mathrm{H}_{2} \mathrm{O}} / \partial z-\left(\partial N_{\mathrm{H}_{2} \mathrm{O}} / \partial z\right)_{0}\right]=v h_{\mathrm{H}_{2} \mathrm{O}}^{-1} N_{\mathrm{H}_{2} \mathrm{O}}\left(1-\beta_{v} / \beta\right)=$ $w_{\bar{E}} N_{\mathrm{H}_{2} \mathrm{O}} \times 0.82$ at $\nu=w_{\bar{E}} h_{\mathrm{H}_{2} \mathrm{O}}$. Thus, the account of eddy flux reduces the estimate of vertical velocity $w_{\bar{E}}$ by 1.82 times, from $w_{\bar{E}}=\bar{E} / F_{w}$, Eq. (17), to $w_{\bar{E}}=\bar{E} /\left(F_{w}+F_{v}\right)=1.3 \mathrm{~mm} \mathrm{~s}^{-1}$. The resulting estimate of the global mean eddy diffusion coefficient $\nu=3.3 \mathrm{~m}^{2} \mathrm{~s}^{-1}$ practically coincides with the phenomenological value. This lends further support to the statement that the observed turbulent processes in the atmosphere and atmospheric circulation are ultimately conditioned by the process of evaporation of water vapor from the Earth's surface at the observed $\Gamma_{o b}=6.5 \mathrm{~K} \mathrm{~km}^{-1}$ and are generated by the evaporative force, Eq. (16). Finally, we note that the evaporative force equally acts on all gases irrespective of their molar mass, so when the ascending air parcels expand, the relative amount of the various dry air components does not change. This explains the observed constancy of dry air molar mass $M_{d}$ (i.e. constant mixing ratios of the dry air constituents) over height $z$. 


\subsection{Horizontal fluxes of atmospheric moisture and air}

Based on the physical grounds discussed in the previous two sections, it is possible to formulate the following physical principle of atmospheric motion. If evaporation fluxes in two adjacent areas are different, the ascending fluxes of moist air are different as well. Therefore, there appear horizontal fluxes of moist air from the area with weaker evaporation to the area where evaporation is more intensive. The resulting directed moisture flow will enhance precipitation in the area with strong evaporation and diminish precipitation in the area with weak evaporation. In particular, it is possible that moisture will be brought by air masses from dry to wet areas, i.e. against the moisture gradient. This is equivalent to the existence of a moisture pump supported by the energy spent on evaporation. This pattern provides clues for several important phenomena.

First, it explains the existence of deserts bordering, like Sahara, with the ocean. In deserts where soil moisture stores are negligible, evaporation from the ground surface is practically absent. Atmospheric water vapor is in the state of aerostatic equilibrium, Eq. (10), so the evaporative force, Eq. (16), in desert is equal to zero. In contrast, evaporation from the oceanic surface is always substantial. The upwarddirected evaporative force is always greater over the ocean than in the desert. It makes oceanic air rise and effectively "sucks in" the desert air to the ocean, where it replaces the rising oceanic air masses at the oceanic surface, Fig. 4a. The reverse ocean-to-desert air flux occurs in the upper atmosphere, which is depauperate in water vapor. This moisturepoor air flux represents the single source of humidity in the desert. Its moisture content determines the stationary relative humidity in the desert. To sum up, due to the absence of surface evaporation, deserts appear to be locked for oceanic moisture year round, Fig. 4a.

In less arid zones like savannas, steppes, irrigated lands, some non-zero evaporation from the surface is present throughout the year. Land surface temperature undergoes greater annual changes than does the surface temperature of the thermally inert ocean. In winter, the ocean can be warmer than land. In such a case partial pressure $p_{\mathrm{H}_{2} \mathrm{O}}$ of water vapor in the atmospheric column over the ocean is higher than on land. The evaporative force is greater over the ocean as well. In the result, a horizontal land-to-ocean flux of air and moisture originates, which corresponds to the well-known phenomenon of winter monsoon (dry season), Fig. 4b.

In contrast, as the warm season sets in, land surface heats up more quickly than does the ocean and, despite the preceding dry winter season, the evaporation flux from the land surface can exceed the evaporation flux over the colder ocean. There appears an air flux transporting oceanic moisture to land known as summer monsoon (rainy season), Fig. 4c. In the beginning, only the wettest part of land, the coastal zone, can achieve an evaporation flux in excess of the oceanic one. This initiates the fluxes of moist air, precipitation and fur- ther enhances terrestrial evaporation. As the evaporation flux grows, so do the fluxes of moist air from the ocean. They gradually spread inland to the drier parts of the continent and weaken exponentially with distance from the ocean, see Eqs. (1), (3) and Fig. 2a. Notably, an indispensable condition for summer monsoon is the considerable store of water on land, which sustains appreciable evaporation year round. In deserts, in spite of even greater seasonal differences between land and ocean surface temperatures, the evaporation on land is practically absent, so no ocean-to-land fluxes of moisture can originate in any season.

Although the vegetation of savannas does support some non-zero ground stores of moisture and fluxes of evaporation, the absence of a contiguous cover of tall trees with high leaf area index prevents such ecosystems from increasing evaporation up to a level when the appearing flux of atmospheric moisture from the ocean would compensate runoff from the optimally moistened soil. The biotic pump of atmospheric moisture does not work in such scarcely vegetated ecosystems; precipitation weakens exponentially with distance from the ocean, Fig. 2 a.

The phenomenon of trade winds (Hadley circulation) can also be explained on these grounds. As far as in the stationary case solar radiation is the source of energy for evaporation, the increase of the solar flux towards the equator should be accompanied by a corresponding increase of evaporation flux $E$, evaporative force $f_{E}$, Eq. (16), and vertical velocity $w$, Eq. (17). The intensive ascent of moist air on the equator has to be compensated by horizontal air fluxes originating at higher latitudes and moving towards the equator, where they ascend and travel back in the upper atmosphere, Fig. 4d. Subsidence of dry air masses at the non-equatorial border of Hadley cells diminishes water vapor concentration in these areas, producing an additional, unrelated to the geography of solar radiation, decrease of the evaporative force. This creates favorable conditions for Ferrel circulation, i.e. movement of air masses from subtropics to higher latitudes.

Finally, natural forest ecosystems can ensure the necessary ocean-to-land flux of atmospheric moisture in any direction. Due to the high leaf area index, which is equal to the total area of all leaves of the plant divided by the plant projection area on the ground surface, the cumulative evaporative surface of the forest can be much higher than the open water surface of the same area. Forest evaporation can be several times higher than the evaporation flux in the ocean, approaching the maximum possible value limited by solar radiation. Maximum evaporation, corresponding to the global mean solar flux absorbed by the Earth's surface $I=150 \mathrm{~W} \mathrm{~m}^{-2}$, is about $I /\left(\rho_{l} Q_{\mathrm{H}_{2} \mathrm{O}}\right) \approx 2 \mathrm{~m}$ year $^{-1}$, where $\rho_{l}=5.6 \times 10^{4} \mathrm{~mol} \mathrm{~m}^{-3}$ is the molar density of liquid water. (Note that this maximum evaporation does not depend on surface temperature.) Global evaporation from the oceanic surface is substantially lower, about $1.2 \mathrm{~m} \mathrm{year}^{-1}$ (L'vovitch, 1979). Intensive ascending fluxes of moist air generated by forest evaporation induce the compensating low-level horizontal influx of moisture-laden 
(a)

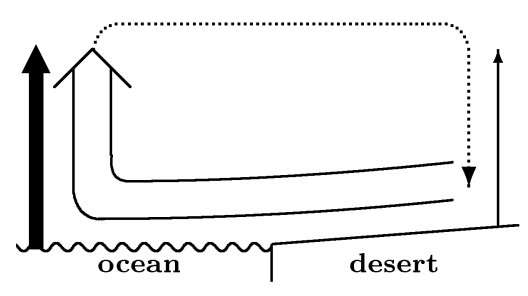

desert locked for moisture (b)

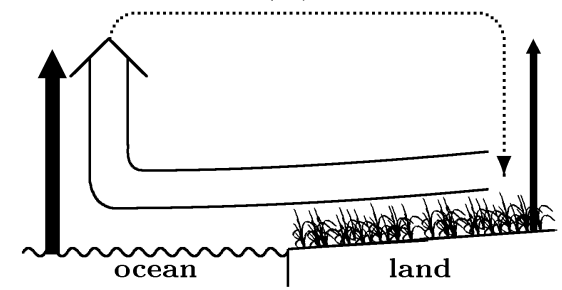

winter monsoon (c)

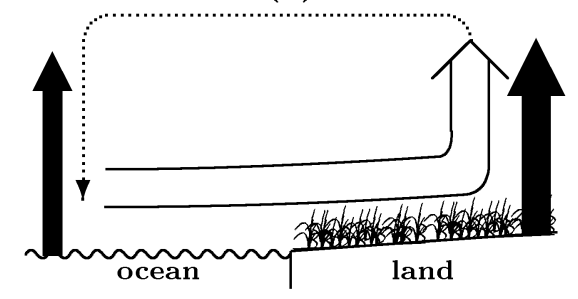

summer monsoon (d)

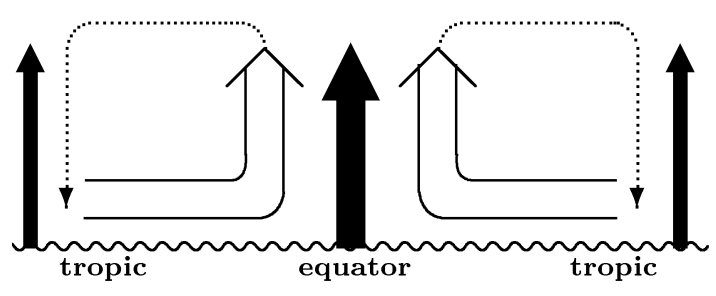

Hadley circulation (e)

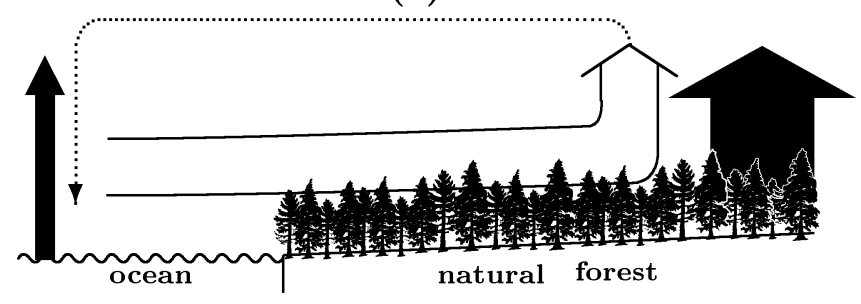

biotic pump of atmospheric moisture

Fig. 4. The physical principle that the low-level air moves from areas with weak evaporation to areas with more intensive evaporation provides clues for the observed patterns of atmospheric circulation. Black arrows: evaporation flux, arrow width schematically indicates the magnitude of this flux (evaporative force). Empty arrows: horizontal and ascending fluxes of moisture-laden air in the lower atmosphere. Dotted arrows: compensating horizontal and descending air fluxes in the upper atmosphere; after condensation of water vapor and precipitation they are depleted of moisture. (a) Deserts: evaporation on land is close to zero, so the low-level air moves from land to the ocean year round, thus "locking" desert for moisture. (b) Winter monsoon: evaporation from the warmer oceanic surface is larger than evaporation from the colder land surface; the low-level air moves from land to the ocean. (c) Summer monsoon: evaporation from the warmer land surface is larger than evaporation from the colder oceanic surface; the low-level air moves from ocean to land. (d) Hadley circulation (trade winds): evaporation is more intensive on the equator, where the solar flux is larger than in the higher latitudes; low-level air moves towards the equator year round; seasonal displacements of the convergence zone follow the displacement of the area with maximum insolation. (e) Biotic pump of atmospheric moisture: evaporation fluxes regulated by natural forests exceed oceanic evaporation fluxes to the degree when the arising ocean-to-land fluxes of moist air become large enough to compensate losses of water to runoff in the entire river basin year round.

air from the ocean. When the incoming air fluxes ascend, the oceanic moisture condenses and precipitates over the forest. Unburdened of moisture, dry air returns to the ocean from land in the upper atmosphere.

As far as in the natural forest with high leaf area index evaporation, limited by solar radiation only, can exceed evaporation from the ocean all year round, the corresponding horizontal influx of oceanic moisture into the forest can persist throughout the year as well, Fig. 4e. Here lies the difference between the undisturbed natural forest and open ecosystems with low leaf area index. In open ecosystems with low leaf area index the ocean-to-land flux can only originate when the land surface insolation and temperature are higher than on the oceanic surface, Figs. 4b, c.

Total force causing air above the natural forest canopy to ascend is equal to the sum of local evaporative forces generated by local evaporation fluxes of individual trees. On the other hand, this cumulative force acts to pump the at- mospheric moisture inland from the ocean via the coastline. Therefore, the total flux $F(0)$ of moisture from the ocean to the river basin, which compensates the total runoff, is proportional to the number of trees in the forest and, consequently, to the area of the forest-covered river basin. According to the law of matter conservation (continuity equation), the horizontal flux of moisture via the vertical cross-section of the atmospheric column along the coastline, $F(0)=W_{a} u D h$, where $D$ is the coastline length (basin width), $h$ is the height of moist atmospheric column, $u$ is horizontal air velocity and $W_{a}\left(\mathrm{~kg} \mathrm{H}_{2} \mathrm{O} \mathrm{m}^{-2}\right)$ is the moisture content in the atmospheric column, should be equal to the ascending flux of moisture across the horizontal cross-section of the atmospheric column above the entire river basin of area $D L$, which is equal to $W_{a} w_{\mathrm{f}} D L$, where $w_{\mathrm{f}}$ is the vertical velocity of air motion. From this we obtain $w_{\mathrm{f}}=u h / L$.

The magnitudes of the velocities $w_{\mathrm{f}}$ and $u$ are determined by the condition that the power developed by the 
evaporative force in the atmospheric column above the forest canopy is equal to the power of dissipation of the horizontal air fluxes near the Earth's surface. The power $A_{E}$ of the evaporative force $f_{E}$ over the forest canopy is equal to $A_{E}=f_{E} w_{\mathrm{f}} h_{\mathrm{H}_{2} \mathrm{O}} D L \sim \rho\left(\beta-\beta_{v}\right) \gamma_{s} g w_{\mathrm{f}} h_{\mathrm{H}_{2} \mathrm{O}} D L$, see Eq. (16). The power of dissipation $A_{f r}$ associated with the friction force $f_{f r}$ is equal to $A_{f r}=f_{f r} u z_{s} D L$. Friction force is equal to $f_{f r}=\rho v \partial^{2} u / \partial z^{2}=\rho v u / z_{s}^{2}$ (Lorenz, 1967), where $z_{s}$ is the height of the surface layer where velocity $u$ changes rapidly with height due to substantial friction. Taking into account that $v \sim w_{\mathrm{f}} h_{\mathrm{H}_{2} \mathrm{O}}$, we have $f_{f r}=\rho w_{\mathrm{f}} h_{\mathrm{H}_{2} \mathrm{O}} u / z_{s}^{2}$. Equating powers $A_{E}$ and $A_{f r}$ we obtain $\left(\beta-\beta_{v}\right) \gamma_{s} g \sim u^{2} / z_{s}$. Taking $z_{s} \sim 25 \mathrm{~m}$ and $\gamma_{s} \sim 2 \times 10^{-2}$, we obtain an estimate of the horizontal velocity $u \sim 4 \mathrm{~m} \mathrm{~s}^{-1}$, which coincides in its order of magnitude with the observed global mean wind speed (Gustavson, 1979).

Horizontal velocity $u$ sufficient for the compensation of the river runoff $R$ from the optimally moistened soil in the river basin of area $D L$ covered by natural forest is calculated from the relationship $R D L=W_{a} u D$. For example, for the tropical Amazon we have $R \sim 10^{3} \mathrm{~kg} \mathrm{H}_{2} \mathrm{O} \mathrm{m}{ }^{-2}$ year $^{-1}$ (Marengo, 2004), $W_{a} \sim 50 \mathrm{~kg} \mathrm{H}_{2} \mathrm{O} \mathrm{m}^{-2}$ (Randel et al., 1996) and $L \sim 3000 \mathrm{~km}$, Fig. $2 \mathrm{~b}$, so $u=R L / W_{a} \sim 1.6 \mathrm{~m} \mathrm{~s}^{-1}$ and $w_{\mathrm{f}}=R h / W_{a} \sim 5.6 \mathrm{~mm} \mathrm{~s}^{-1}$ at $h=8.4 \mathrm{~km}$, see Eq. (10). It follows from the relationship $w_{\mathrm{f}}>w_{\bar{E}} \approx 1.3 \mathrm{~mm} \mathrm{~s}^{-1}$, (where the estimate of $w_{\bar{E}}$, Eq. (17), is corrected taking into account the turbulent flux of water vapor, as discussed above) that only undisturbed natural forests with closed canopies and high leaf area index can maintain optimal soil moisture content at any distance from the ocean at the expense of pumping atmospheric moisture from the ocean. This is because only such ecosystems are able to ensure evaporation fluxes greatly exceeding the fluxes of evaporation from the open water surface of the ocean.

The outlined principles of horizontal air motions, Fig. 4a$\mathrm{e}$, allow one to make several generalizations. First, if the coastal zone of width $l \sim 600 \mathrm{~km}$ is deforested, the flow of oceanic moisture to the inner part of the continent is switched off, thus dooming the inner continental forest to perish. On the other hand, a narrow band of forest along the coast cannot develop a power high enough for pumping atmospheric moisture from the ocean in amounts sufficient for keeping the entire continent moistened and for supporting powerful river systems. Moreover, if the inner part of the continent is turned to an extensive desert with negligible evaporation, the originating horizontal land-to-ocean air fluxes, cf. Fig. 4a, may become more powerful than the small ocean-to-land air fluxes maintained by the narrow forest band near the coast. In such a case the forest will aridify and die out despite its immediate closeness to the open water surface of the ocean or inner sea. Third, as far as the direction and velocity of horizontal air motions is dictated by the difference in evaporative forces between the considered areas, it should apparently be easier for the biota to pump atmospheric moisture from a cold ocean with low evaporation, i.e. from an ocean situated in higher latitudes than the forested river basin itself. This explains the stable existence of the forested basins of the Great Siberian Rivers.

In the meantime, pumping of atmospheric moisture to land from a warm ocean, which is realized in the tropical river basins, is a more complex problem. If the flux of evaporation from the warm oceanic surface exceeds the evaporation flux from the forest canopy, there appears a land-to-ocean flux of atmospheric moisture, which, together with the river runoff, will act to deplete forest moisture stores. To avoid this, it is necessary for the forest to maintain high evaporation at all times. Even if during the most unfavorable season of the warmest oceanic temperatures this flux will nevertheless prevent the moisture of the atmospheric column above the forest from being blown away to the ocean. Thus, we come to a non-trivial conclusion that the more moisture is evaporated from the land surface, the less moisture is lost by land. High transpiration rates observed in the Amazon forests during the dry season (da Rocha et al., 2004) can well serve this goal.

In the next section we consider the physical principles of efficient moisture retention under the closed canopy, which prevent uncontrollable losses of atmospheric moisture and allow the trees to maintain high transpiration power independent of rainfall fluctuations.

\subsection{Water preservation by closed canopies}

In natural forest ecosystems with well-developed closed canopies the daytime air temperature increases in the upward direction, i.e. it is higher in the canopy than at the ground surface (Shuttleworth, 1989; Kruijt et al., 2000; Szarzynski and Anhuf, 2001), because the incoming solar radiation is predominantly absorbed in the canopy. When canopy temperature $T_{c}$ exceeds ground temperature $T_{g}$, the under-canopy lapse rate becomes negative, $\Gamma=-d T / d z \approx\left(T_{c}-T_{g}\right) / z_{c}<0$, where $z_{c}$ is the canopy height reaching several tens of meters in natural forests. As far as $\Gamma<0<\Gamma_{\mathrm{H}_{2} \mathrm{O}}=1.2 \mathrm{~K} \mathrm{~km}^{-1}$, in this case, according to the results of the previous sections, water vapor under the canopy remains in aerostatic equilibrium. Evaporation from soil and the upward fluxes of water vapor from beneath the canopy are absent. Water vapor partial pressure $p_{v}$ conforms to Eq. (10) (with $p_{i}$ and $h_{i}$ changed for $p_{v}$ and $h_{v}$, respectively) and remains practically constant under the canopy with $z_{c} \ll h_{v}, p_{v}(z) \approx p_{v}(0) \equiv p_{v s}$. Relative humidity $R H(z)$, which is equal to $100 \%$ immediately above the wet soil surface, decreases with height as $R H(z)=1 / \exp \left\{\left[T_{\mathrm{H}_{2} \mathrm{O}} / T_{s}\right]-\left[T_{\mathrm{H}_{2} \mathrm{O}} / T(z)\right]\right\}$, cf. Eqs. (10) and (11) and see (Szarzynski and Anhuf, 2001) for data.

The daytime aerostatic equilibrium of the saturated water vapor above the ground surface under the closed canopy prevents biotically uncontrolled losses of soil water to the upper atmosphere. This mechanism explains why the ground surface of undisturbed closed-canopy forests always remains wet, which is manifested as low fire susceptibility of undisturbed natural forests with closed canopies (Cochrane et al., 
1999; Nepstad et al., 2004). In higher latitudes, where the solar angle is lower than in the tropics and solar beams at midday are slanting rather than perpendicular to the surface, the daytime temperature inversion within the canopy can arise at a lesser degree of canopy closure than in the tropics, as far as the lower solar angle diminishes the difference in the solar radiation obtained by canopy and inter-canopy patches, e.g., Breshears et al. (1998).

At nighttime soil surface under the closed canopy is warmer than the canopy due to the rapid radiative cooling of the latter (Shuttleworth et al., 1985; Szarzynski and Anhuf, 2001). The observed temperature lapse rate $\Gamma_{o b}$ is positive and can exceed the mean global value of $6.5 \mathrm{~K} \mathrm{~km}^{-1}$ by dozens of times (Szarzynski and Anhuf, 2001). This leads to a very high value of the compression coefficient $\beta$, Eq. (13), for water vapor. Water vapor is saturated in the entire atmospheric column under the canopy. For example, in the tropical forests of Venezuela the nighttime lapse rate under the canopy is about $\Gamma_{o b}=70 \mathrm{~K} \mathrm{~km}^{-1} \gg \Gamma_{\mathrm{H}_{2} \mathrm{O}}$ (Szarzynski and Anhuf, 2001), which corresponds to $\beta=36$, see Eq. (13). Relative humidity under the canopy is then equal to $100 \%$ at all heights. In spite of the huge evaporative force, Eq. (16) that arises at large values of $\beta$, the ascending fluxes of air under the closed canopy of natural forests remain small due to the high aerodynamic resistance of the trees.

Above the closed canopy, as well as on open areas like pastures and within open canopies, e.g., (Mahrt et al., 2000), nighttime temperature inversions are common, caused by the rapid radiative cooling of the ground surface or canopy. Air temperature increases with height up to several hundred meters (Karlsson, 2000; Acevedo et al., 2004). Temperature inversions result in the condensation of water vapor in the lower cooler layer near the surface (or canopy) often accompanied by formation of fog. As far as at $\Gamma<0<\Gamma_{\mathrm{H}_{2} \mathrm{O}}$ there are no ascending fluxes of water vapor, fog moisture remains near the ground surface $z=0$. However, with increasing solar heating during the daytime and $\Gamma$ growing up to $\Gamma>\Gamma_{\mathrm{H}_{2} \mathrm{O}}$, there appear upward water vapor fluxes. On open areas and areas covered by low vegetation, fog moisture is then taken away from the ground layer to the upper atmospheric layers and ultimately leaves the ecosystem. By contrast, fog formed at night above the closed canopy at $z=z_{c}$ gravitates to the ground layer $z=0$ under the canopy, where during the daytime the moisture is prevented from leaking to the upper atmosphere by the daytime temperature inversion.

This analysis illustrates that both large canopy height and high degree of canopy closure inherent to undisturbed natural forests are important for efficient soil water retention.

During the day air temperature above the forest canopy rapidly decreases with height, $\Gamma \gg \Gamma_{\mathrm{H}_{2} \mathrm{O}}$ (Szarzynski and Anhuf, 2001). Transpiration of water vapor from the leaf stomata lead to formation of an ascending flux of water vapor and air, which supports clouds. When stomata are closed and transpiration ceases, the ascent of air masses discontinues as well. The evaporative force $f_{E}$, Eq. (16), vanishes; liquid atmospheric water, no longer supported, precipitates under gravity. Precipitation fluxes can be additionally regulated by the biota via directed change of various biogenic condensation nuclei. Observations indicate that stomata of most plants close during the midday (Bond and Kavanagh, 1999; Goulden et al., 2004). This allows one to expect that precipitation on land should predominantly occur in the second part of the day. In the ocean, where there is no diurnal biological cycle of water vapor ascent, the diurnal cycle of precipitation is not expected to be pronounced either. These predictions are in agreement with the available data on the diurnal cycle of rainfall in the tropics (Nesbitt et al., 2003).

\section{Biological principles of the biotic pump of atmo- spheric moisture}

Based on the analysis of the spatial distribution of precipitation over forested and non-forested areas, in Sect. 2 we demonstrated that the biotic pump of atmospheric moisture must exist, as follows from the law of matter conservation and the small length $l \sim 600 \mathrm{~km}$ of the physical dampening of precipitation fluxes on land. In Sect. 3 the physical principles of the biotic pump were described. Regarding the ecological and biological grounds of its functioning, the inherently complex applications of the laws of physics by natural forest ecosystems have been refined and polished during the hundred million years of evolution, so it will hardly be ever possible to study them in detail. However, it is worthy to check that the existence of the biotic moisture pump does not contradict the known biological principles of life organization.

Moisture enters a forest-covered river basin via the linear coastline, while it is spent on the two-dimensional area of the basin. Area-specific loss of water to runoff is independent of distance $x$ from the ocean, $R(x)=R(0)$, due to the constant moisture content $W(x)=W(0)$ of the uniformly moistened forest soil, Sect. 2. Thus, the atmospheric flux of moisture via the coastline (dimension $\mathrm{kg} \mathrm{H}_{2} \mathrm{O} \mathrm{m}^{-1} \mathrm{~s}^{-1}$ ), which compensates river runoff in a river basin of length $L$ ( $L$ is counted inland from the coast), $F(0)=\int_{0}^{L} R(x) d x$, should grow linearly with basin length $L, F(0)=R(0) L$. The biotic moisture pump works to ensure this effect. Without biotic pump the value of $F(0)$ would be independent of $L$, cf. Eq. (1), $R(x)$ would exponentially decrease with growing distance $x$ from the ocean, while the mean basin runoff would decrease inversely proportionally to $L$, Sect. 2 .

The problem of meeting the demand of matter or energy of an $n$-dimensional area ( $n=2$ for the river basin) by a flux of matter or energy via an $(n-1)$-dimensional area (one-dimensional coastline of the river basin) is a fundamental biological problem repeatedly faced by life in the course of evolution. Living organisms consume energy via the two-dimensional body surface and spend it within the three-dimensional body volume. In very much the same manner as local runoff and precipitation in natural forests are 
maintained independent of the distance from the ocean, living cells are supplied by an energy flux that is on average independent of the size of the organism.

Analysis of the metabolic power of living organisms from bacteria to the largest mammals revealed that, independent of organismal body size, mean energy consumption of living tissues constitutes $1-10 \mathrm{~W} \mathrm{~kg}^{-1}$ (Makarieva et al., 2005a,b,c). The smallest organisms like unicells can satisfy their energetic needs at the expense of passive diffusion fluxes of matter, if their linear body size $L$ is much less than the scale length $l$ of exponential weakening of the diffusion matter fluxes. For example, bacteria have to transport the food obtained via cell surface over less than one micron (bacterial cell length), while the distance between elephant's trunk (the food-gathering organ) and its brain or heart is about ten million times longer. Passive diffusion fluxes cannot meet the energetic demands of large organisms with $L \gg l$. Thus, large organisms had to invent active pumps (e.g., lungs, heart), which pump matter and energy into the organism and distribute them within it. Similarly, biotically noncontrolled geophysical fluxes of moisture can ensure sufficient soil moistening at small distances $L \ll l$ from the ocean, while to keep large territories with $L \gg l$ biologically productive, the biotic pump of atmospheric moisture is necessary.

Biological pumps like lungs or heart, which supply living cells of large organisms with energy and matter, are complex mechanisms. They have evolved in the course of natural selection of individual organisms possessing most efficient pumps in the population. The biotic pump of atmospheric moisture, grounded in plant physiology and including sensing of the environmental parameters and reaction to their change by a corresponding change in the physiological state of the plant (e.g., stomata opening/closure), is also a complex, highly-ordered biotic mechanism. However, in contrast to an individual organism of a given body size, natural forest ecosystem of linear size $L$ is not an object of natural selection, as it consists of a large number of competing individuals like, e.g., trees. A fundamental theoretical question is therefore how the biotic pump of atmospheric moisture or any other biotic mechanisms regulating regional or global environmental parameters could have been produced by natural selection which acts on individual organisms.

The discussion around this question has already a several decades' history in the biological literature, e.g., Doolittle (1981); Baerlocher (1990), and is largely organized along two opposing lines of reasoning. The first attitude (shared, among others, by many supporters of the Gaia hypothesis) is that the state when ecosystem as a whole regulates regional or global environment for its benefit appears is the most probable macroscopic physical property of the ecosystem, like Maxwell's or Boltzmann's distributions characterizing gas as a whole rather than particular molecules. No natural selection is needed for such a state to become established.

The opponents of this attitude implicitly recognize that the biotic control of any environmental conditions is a very com- plex process having nothing to do with the physical processes of thermodynamics (either linear, or non-linear). As such, it could have only evolved as the product of natural selection, like any other complex function of living organisms. However, continue the opponents, one individual performing some job on environmental regulation makes the regional environment slightly better for all individuals, including those who do nothing. Hence, individuals capable of environmental control do not have a selective advantage over their conspecifics. Moreover, doing something for the global environment, the regulators spend their metabolic energy and can therefore lose to the non-regulators who spend all their energy on competitive interaction. Thus, since natural selection cannot favor regulatory capabilities on the individual level, the biotic control of regional or global environment could not have appeared in the course of biological evolution and, hence, it does not exist.

Most recently, this logical opposition could be followed in the discussion of A. Kleidon (first attitude) and V. Arora (second attitude) (Kleidon, 2004, 2005; Arora, 2005). The contradiction between the observational evidence lending support to the existence of biotic mechanisms of environmental control, including the biotic pump of atmospheric moisture, and the apparent impossibility of finding a logically coherent physical and biological explanation of this evidence, prevents the wide scientific recognition of the decisive role the natural ecosystems play in maintaining the environment in a state suitable for life, including the biotic control of water cycle on land.

This contradiction is solved in the biotic regulation concept (Gorshkov, 1995; Gorshkov et al., 2000). First, it was shown that the degree of orderliness of ecological and biological systems is about twenty orders of magnitude higher than the degree of orderliness of any of the so-called physically self-organized open non-linear systems (Gorshkov and Makarieva, 2001). Natural selection of competing biological objects (individuals) is the only way by which the biological information accumulates in the course of evolution. Therefore, any highly organized life property, including the biotic pump of atmospheric moisture, can only originate as a product of natural selection.

Second, a fundamental parameter of the biotic sensitivity $\varepsilon$ was introduced (Gorshkov, 1984, 1995; Gorshkov et al., 2000; Gorshkov et al., 2004), which, if finite, makes it possible for various biotic mechanisms of global environmental control (including the biotic pump of atmospheric moisture) to originate in the course of natural selection acting on individual organisms (trees). Under tree below we shall understand an individual tree together with all the other organisms of the ecological community that are rigidly correlated with this tree (e.g., soil bacteria and fungi). Each tree works to maintain optimal soil moisture conditions on the area it occupies. If the occasional relative change of soil moisture content under the tree is less than $\varepsilon$, the tree does not react to it. According to our estimates (Gorshkov et al., 
2000; Gorshkov et al., 2004), biotic sensitivity with respect to changes of major environmental parameters is of the order of $\varepsilon \sim 10^{-2}-10^{-3}$. Trees' ability to remain highly sensitive to environmental conditions is genetically programmed via individual selection of trees with $\varepsilon<10^{-2}$. Those individuals who have lost this ability and have a poor sensitivity $\varepsilon>10^{-2}$, suffer from large fluctuations of local soil moisture content, which adversely affect their biological performance. Such trees lose competitiveness and are forced out from the population by normal trees with $\varepsilon<10^{-2}$.

If the local soil moisture content occasionally deviates from its optimum value by a relative amount exceeding biotic sensitivity $\varepsilon$, the tree does notice this change and initiates compensating environmental processes in order to increase or decrease the local moisture content restoring the optimal conditions. Environmental impact of the tree can take a variety of forms, including change of transpiration fluxes via stomata opening/closure, regulation of the vertical temperature gradient below the canopy, facilitation of precipitation by biogenic aerosols, and other unknown processes, of which some are possibly unknowable due to the high complexity of the object under study. On average, functioning of the tree results in pumping moisture out of the atmosphere and increase of the local precipitation, which compensates for the local losses of soil water to runoff. If the environmental changes performed by the tree lead to optimization of the local soil moisture content to the accuracy of the biotic sensitivity $\varepsilon$, the tree and its associated biota acquire competitive advantage over neighboring trees incapable of performing the needed environmental changes. These deficient neighbors lose in competition with, and are replaced by, normal trees capable of environmental control. In the result, all trees remaining in the forest are genetically programmed to act in one and the same direction, thus forming a regional biotic pump of atmospheric moisture, which compensates for the river runoff. At the same time, individual trees continue to compete with each other, and forest as a whole does not have a "physiology" of a superorganism.

\section{Conclusions}

In this paper we introduced and described the biotic pump of atmospheric moisture. It makes use of the fundamental physical principle that horizontal fluxes of air and water vapor are directed from areas with weaker evaporation to areas with stronger evaporation. Natural forest ecosystems, with their high leaf area index and high evaporation exceeding evaporation from open water surface, are capable of pumping atmospheric moisture from the ocean in amounts sufficient for the maintenance of optimal soil moisture stores, compensating the river runoff and ensuring maximum ecosystem productivity.

The biotic moisture pump, as well as the mechanisms of efficient soil moisture preservation described in Sect. 3.4, work in undisturbed natural forests only. Natural forest represents a contiguous cover of tall trees that are rigidly associated with other biological species of the ecological community and genetically programmed to function in the particular geographic region. The vegetation cover of grasslands, shrublands, savannas, steppes, prairies, artificially thinned exploited forests, plantations, pastures or arable lands is unable to switch on the biotic moisture pump and maintain soil moisture content in a state optimal for life. Water cycle on such territories is critically dependent on the distance from the ocean; it is determined by random fluctuations and seasonal changes of rainfall brought from the ocean. Such territories are prone to droughts, floods and fires. We emphasize that the contemporary wide spread of scarcely vegetated ecosystems, in particular, African savannas, is rigidly correlated with anthropogenic activities during the last several thousand years (see, e.g., Tutin et al., 1997). Savannas represent a succesional state of the ecosystem returning to its undisturbed forest state; this transition spontaneously occurs as soon as the artificial disturbances like fire and overgrazing are stopped (van de Koppel and Prins, 1988). Since savannas and other open ecosystems suffer from rapid soil erosion (Lal, 1990), their prolonged existence is only possible due to continuous cycling with the forest state, when the mineral and organic content of soil is restored. Therefore, the growing anthropogenic pressure on savannas, which prevents their periodic transitions to forests, gradually turns savannas to deserts. The same is true for steppes and prairies of the temperate zone.

Only primary aboriginal forests are able to ensure the long-term stability of the biotic moisture pump functioning, as far as the genetic properties of aboriginal forests are correlated with the geophysical properties of the region they occupy. Artificially planted exotic vegetation with geographically irrelevant genetic programs cannot persist on an alien territory for a long time; their temporal prosperity is followed by environmental degradation and ecological collapse. On the other hand, secondary aboriginal forests that are in the process of self-recovery from anthropogenic or natural disturbances like fires, cutting or windfall, are not capable of efficiently running the biotic pump either. In such forests all mechanisms of environmental regulation, including the biotic moisture pump, are under repair and cannot yet function efficiently.

For the biotic moisture pump to work properly, it is also important that the natural forest cover have an immediate border with the ocean or, at least, the distance to the ocean be much less than the scale length $l$, Eq. (1), of the exponential weakening of the ocean-to-land moisture fluxes observed over non-forested regions. The two largest tropical river basins of Amazon and Congo are covered by rainforests spreading inland from the oceanic coastline. Northern river basins of Russia, Canada and Alaska are covered by natural taiga forests, which, at the northernmost forest line, border with tundra wetlands linking them to the oceanic coast. If the 
natural forest cover is eliminated along the oceanic coastline on a band $l \sim 600 \mathrm{~km}$ wide, the biotic moisture pump stalls. The remaining inland forests are no longer able to pump atmospheric moisture from the ocean. There is no longer surplus to runoff to rivers or to recharge groundwater. Soil water either leaves to the ocean as runoff or is blown away via the atmosphere after being transpired by the forests. The river basin ceases to exist, the forests die back after the soil dries up. The total store of fresh water on land including the water of soil, bogs, mountain glaciers and lakes, can be estimated by the lake store alone and constitutes around $1.5 \times 10^{14} \mathrm{~m}^{3}$ (L'vovitch, 1979), while the global river runoff is of the order of $0.37 \times 10^{14} \mathrm{~m}^{3} \mathrm{yr}^{-1}$ (Dai and Trenberth, 2002). This means that all liquid moisture accumulated on land runs to the ocean in about four years. Total destruction of the biotic moisture pump due to deforestation (i.e., complete elimination of the contiguous forest cover bordering with the ocean) will in several years turn any river basin to desert.

In Australia, the continent-scale forested river basins ceased to exist about 50-100 thousand years ago, a time period approximately coinciding with the arrival of first humans. There is a host of indirect evidence suggesting that humans are responsible for the ancient deforestation of the Australian continent (see discussion in Bowman, 2002). It is clear how this could have happened. To deforest the continent, it was enough to destroy forests on a narrow band of width $l$ along the continent's perimeter. This could be easily done by the first human settlements in the course of their household activities or due to the human-induced fires. This done, the biotic water pump of the inner undisturbed forested part of the continent was cut off from the ocean and stalled. Rapid runoff and evaporation eliminated the stores of soil moisture and the inland forests perished by themselves even in the absence of intense anthropogenic activities or fires in the inner parts of the continent. As estimated above, this forest-to-desert transition should have been instantaneous on the geological time scale, so it is not surprising that practically no paleodata were left to tell more details about this ecological catastrophe. Notably, most deserts of the world border with the ocean or inner seas. As far as the coastal zone is the preferred area for human settlements, the modern extensive deserts of Earth should all be of anthropogenic origin.

Modern practice of forest cutting and exploitation, which is responsible for the unprecedented high rate of deforestation world over (Bryant et al., 1997), was born in Western Europe. Remarkably, in this part of land there are no areas separated from the ocean or inner seacoast by more than $l \sim 600 \mathrm{~km}$, the scale length of exponential weakening of the ocean-to-land moisture fluxes in non-forested areas, Sect. 2.1. Therefore, elimination of natural European forests, which today is being finalized in Scandinavia, has not led to complete desertification of Europe. This worked to support the illusion that the forest cutting tradition can be safely imported to the other parts of the planet, despite the accumu- lating evidence about the disastrous consequences of such practices when applied to vast continental areas. Even in Western Europe one has been recently witnessing an increase in catastrophic droughts, fires and floods, likely facilitated by the on-going elimination of the remaining natural forests in the mountains. The decline of Alpine forests, which, via the biotic moisture pump, used to enhance precipitation in the mountains, should have led to the decline of mountain glaciers, although the latter phenomenon is almost exclusively considered in the framework of global warming and atmospheric $\mathrm{CO}_{2}$ build-up, while the biotic pump effects are ignored.

We also note that when the forest cover is (partially) replaced by an artificial water body, like the water storage reservoirs of hydropower plants, the controlling function of forest transpiration and the biotic pump weaken causing reduction of runoff and precipitation in the corresponding river basin.

The results obtained form the basis of a possible strategy to restore human-friendly water conditions on most part of the Earth's landmasses, including modern deserts and other arid zones. As we have shown, elimination of the forest cover in world's largest river basins would have the following consequences: at least one order of magnitude's decline of the river runoff, appearance of droughts, floods and fires, partial desertification of the coastal zone and complete desertification of the inner parts of the continents, see Eqs. (5) and (6), associated economic losses would by far exceed the economic benefits of forest cutting, let alone such a scenario would make life of millions of people impossible. Therefore, it is worthy to urgently reconsider the modern forest policy everywhere in the world. First of all, it is necessary to immediately stop any attempts of destroying the extant natural forest remnants and, in particular, those bordering with the ocean or inner seas. Further on, it is necessary to initiate a world-wide company on facilitating natural gradual recovery of aboriginal forest ecosystems on territories adjacent to the remaining natural forests. Only extensive contiguous natural forests will be able to run a stable water cycle and subsequently intensify it, gradually extending the river basin at the expense of newly recovering territories.

In intact primary forests the relative area of natural disturbances like tree gaps does not exceed 10\% (Coley and Barone, 1996; Szarzynski and Anhuf, 2001). Approximately the same share of land surface is currently exploited by man as arable land, pastures and industrial forest plantations. Therefore, if natural forests are restored over most parts of currently unused arid territories, such a state will be as stable as are the natural forests that have persisted through millions of years. The recovered luxurious water resources on land will be at full disposal of the ecologically literate humanity of the future. 


\section{Appendix A}

\section{Physical basis of the tropospheric lapse rate of air temperature}

The decrease of air temperature with height observed in the troposphere is conditioned by the presence of atmospheric greenhouse substances; however, it is not related to the magnitude of the planetary greenhouse effect.

Greenhouse substances perform resonance absorption of thermal radiation emitted by the Earth's surface and re-emit it isotropically in all directions. Half of the absorbed thermal radiation is re-directed back to the surface. This random walk of thermal photons in the atmosphere results in an increase of the density of radiation energy near the surface and its drop with atmospheric height.

The resulting negative vertical gradient of radiative energy density can be related to the lapse rate of the so-called brightness temperature. It is defined as the temperature of a blackbody, which emits a radiation flux equal to the upward flux of thermal radiation observed at height $z$ in the atmosphere. In the course of inelastic collisional interaction with molecules of the greenhouse substances, air molecules lose their kinetic energy (this energy is imparted to the molecules of the greenhouse substances and ultimately lost into space in the form of thermal radiation). In the result, air temperature approaches brightness temperature of thermal radiation; there appears a negative vertical gradient (lapse rate) of air temperature close to the lapse rate of radiative brightness temperature. It is due to these physical processes that the environmental temperature lapse rate arises.

Thermal radiation spectrum of the Earth's surface is close to the blackbody spectrum at Earth's surface temperature. If the greenhouse substances of the terrestrial atmosphere had but one or a few absorption lines (narrow bands) with respect to thermal radiation, then all the radiation emitted from the Earth's surface, except for those lines, would leave into space unimpeded, without interacting with the atmosphere. Brightness temperature of the entire spectrum, except for those lines, would not change with height. In such a case the surface temperature would coincide with the brightness temperature of thermal radiation emitted into space, i.e. the planetary greenhouse effect would be close to zero.

However, if the amount of greenhouse substances with those narrow absorption bands is large and the absorption lines have large absorption cross-sections, brightness temperature of thermal radiation in the corresponding spectral interval can rapidly drop with height, theoretically down to absolute zero. Collisional excitation of these absorption lines by air molecules would deplete the kinetic energy of the latter, resulting in a decrease of air temperature with height. Thus, there appears a large negative vertical gradient of air temperature, which, as described in Sect. 3, causes the observed upward fluxes of latent heat and evaporation. Condensation of the ascending water vapor with release of latent heat increases air temperature, enhances the collisional excitation of the greenhouse substances and diminishes the lapse rates of both brightness and air temperatures. In the result, the magnitude of the air temperature lapse rates is fixed at the observed value of $\Gamma_{o b}=6.5 \mathrm{~K} \mathrm{~km}^{-1}$.

Therefore, the observed value of $\Gamma_{o b}=6.5 \mathrm{~K} \mathrm{~km}^{-1}$ can be a product of one narrow absorption line with large absorption cross-section present in the atmosphere. The greenhouse substance with that narrow efficient line absorbs all the released latent heat and thermal energy of the dissipating processes of atmospheric circulation, turns this energy into thermal radiation and mainly redirects to the surface. At the surface the radiative energy corresponding to the narrow absorption line is distributed over the entire thermal spectrum and leaves into space.

On the other hand, if the absorption lines of the greenhouse substances covered the whole thermal spectrum of the surface, but they exclusively interacted with thermal photons under conditions of the so-called radiative equilibrium, when the collisional excitation of these lines is negligible, in such a case the planetary greenhouse effect could reach large values (i.e. the planetary surface would be much warmer than in the absence of greenhouse substances), while the lapse rate of air temperature remained close to zero.

Therefore, the magnitudes of the planetary greenhouse effect and air temperature lapse rate $\Gamma$ are not unambiguously related to each other. However, in the absence of all greenhouse substances in the atmosphere, both air temperature lapse rate, evaporative force (Sect. 3.3) and greenhouse effect are all equal to zero.

Acknowledgements. This research uses data provided by the Community Climate System Model project supported by the Directorate for Geosciences of the National Science Foundation and the Office of Biological and Environmental Research of the U.S. Department of Energy. The authors benefited greatly from the constructive criticisms and comments that were put forward during the Discussion of this paper at HESSD. We express our sincere gratitude to all participants of the Discussion.

Edited by: A. Ghadouani

\section{References}

Acevedo, O. C., Moraes, O. L. L., da Silva, R., Fitzjarrald, D. R. Sakai, R. K., Staebler, R. M., and Czikowsky, M. J.: Inferring nocturnal surface fluxes from vertical profiles of scalars in an Amazon pasture, Global Change Biology, 10, 886-894, 2004.

Adler, R. F., Huffman, G. J., Bolvin, D. T., Curtis, S., and Nelkin, E. J.: Tropical rainfall distributions determined using TRMM combined with other satellite and rain gauge, J. Appl. Meteorol., 39, 2007-2023, 2001.

Arora, V.: Comment on "Optimized stomatal conductance of vegetated land surfaces and its effects on simulated productivity and climate" edited by: Kleidon, A., Geophys. Res. Lett., 32, L08708, doi:10.1029/2004GL022110, 2005. 
Austin, A. T. and Sala, O. E.: Carbon and nitrogen dynamics across a natural precipitation gradient in Patagonia, Argentina, J. Vegetation Sci., 13, 351-360, 2002.

Austin, A. T. and Vitousek, P. M.: Precipitation, decomposition and litter decomposability of Metrosideros polymorpha in native forests on Hawaii, J. Ecology, 88, 129-138, 2000.

Baerlocher, F.: The Gaia hypothesis: A fruitful fallacy?, Experientia, 46, 232-238, 1990.

Barrett, J. E., McCulley, R. L., Lane, D. R., Burke, I. C., and Lauenroth, W. K.: Influence of climate variability on plant production and $\mathrm{N}$-mineralization in Central US grasslands, J. Vegetation Sci., 13, 383-394, 2002.

Bond, B. J. and Kavanagh, K. L.: Stomatal behavior of four woody species in relation to leaf-specific hydraulic conductance and threshold water potential, Tree Physiology, 19, 503-510, 1999.

Bowman, D. M. J. S.: The Australian summer monsoon: a biogeographic perspective, Australian Geographic Studies, 40, 261277, 2002.

Breshears, D. D., Nyhan, J. W., Heil, C. E., and Wilcox, B. P.: Effects of woody plants on microclimate in a semiarid woodland: soil temperature and evaporation in canopy and intercanopy patches, Int. J. Plant Sci., 159, 1010-1017, 1998.

Bryant, D., Nielsen, D., and Tangley, L.: The last frontier forests: ecosystems and economies on the edge, World Resources Institute, Washington, 1997.

Cabido, M., Gonzalez, C., Acosta, A., and Diaz, S.: Vegetation changes along a precipitation gradient in central Argentina, Vegetatio, 109, 5-14, 1993.

Canadell, J. G., Steffen, W. L., and White, P. S.: IGBP/GCTE terrestrial transects: Dynamics of terrestrial ecosystems under environmental change - Introduction, J. Vegetation Sci., 13, 297300, 2002.

Cochrane, M. A., Alencar, A., Schulze, M. D., Souza, C. M., Nepstad, D. C., Lefebvre, P., and Davidson, E. A.: Positive feedbacks in the fire dynamic of closed canopy tropical forests, Science, 284, 1832-1835, 1999.

Coley, P. D. and Barone, J. A.: Herbivory and plant defenses in tropical forests, Annual Review of Ecology and Systematics, 27, 305-335, 1996.

Cook, G. D. and Heerdegen, R. G.: Spatial variation in the duration of the rainy season in monsoonal Australia, Int. J. Climatology, 21, 1723-1732, 2001.

da Rocha, H. R., Goulden, M. L., Miller, S. D., Menton, M. C., Pinto, L. D. V. O., de Freitas, H. C., and Silva Figueira, A. M. E.: Seasonality of water and heat fluxes over a tropical forest in eastern Amazonia, Ecological Appl., 14(Suppl), S22-S32, 2004.

Dai, A. and Trenberth, K. E.: Estimates of freshwater discharge from continents: latitudinal and seasonal variations, J. Hydrometeorol., 3, 660-687, 2002.

Doolittle, W. F.: Is nature really Motherly?, CoEvolution Quaterly, 29, 58-63, 1981.

Fang, M. and Tung, K. K.: Time-dependent nonlinear Hadley circulation, J. Atmos. Sci., 56, 1797-1807, 1999.

Folkins, I.: Convective damping of buoyancy anomalies and its effect on lapse rates in the tropical lower troposphere, Atmos. Chem. Phys., 6, 1-12, 2006, http://www.atmos-chem-phys.net/6/1/2006/.

Goody, R. M. and Yung, Y. L.: Atmospheric radiation, theoretical basis, 2nd edn, Oxford Univ. Press, New York, 1989.
Gorshkov, V. G.: Ecology of man, Leningrad Polytechnical Institute, Leningrad, 1984.

Gorshkov, V. G.: Physical and biological bases of life stability, Springer, Berlin, 1995.

Gorshkov, V. G. and Makarieva, A. M.: On the possibility of physical self-organization of biological and ecological systems, Doklady Biological Sci., 378, 258-261, 2001.

Gorshkov, V. G., Gorshkov, V. V., and Makarieva, A. M.: Biotic regulation of the environment: Key issue of global change, Springer, London, 2000.

Gorshkov, V. G., Makarieva, A. M., and Gorshkov, V. V.: Revising the fundamentals of ecological knowledge: The biotaenvironment interaction, Ecol. Complexity, 1, 17-36, 2004.

Goulden, M. L., Daube, B. C., Fan, S.-M., Sutton, D. J., Bazzaz, A., Munger, J. W., and Wofsy, S. C.: Physiological response of a black spruce forest to weather, J. Geophys. Res., 102D, 28987 28 996, 1997.

Goulden, M. L., Miller, S. D., da Rocha, H. R., Menton, M. C., de Freitas, H. C., Silva Figueira, A. M. E., and de Sousa, C. A. D.: Diel and seasonal patterns of tropical forest $\mathrm{CO}_{2}$ exchange, Ecol. Appl., 14(Suppl), S42-S54, 2004.

Gustavson, M. R.: Limits to the wind power utilization, Sci., 204, 13-17, 1979.

Hodnett, M. G., Oyama, M. D., Tomasella, J., and Marques Filho, A. de O.: Comparisons of long-term soil water storage behaviour under pasture and forest in three areas of Amazonia, in: Amazonian deforestation and climate, edited by: Gash, J. H. C., Nobre, C. A., Roberts, J. M., and Victoria, R. L., 57-77, John Wiley \& Sons, Chichester, 1996.

Hutley, L. B., O'Grady, A. P., and Eamus, D.: Monsoonal influences on evapotranspiration of savanna vegetation of northern Australia, Oecologia, 126, 434-443, 2001.

Karlsson, I. M.: Nocturnal air temperature variations between forest and open areas, J. Appl. Meteorol., 39, 851-862, 2000.

Kleidon, A.: Optimized stomatal conductance of vegetated land surfaces and its effects on simulated productivity and climate, Geophys. Res. Lett., 31, L21203, doi:10.1029/2004GL020769, 2004.

Kleidon, A.: Reply to comment by V. Arora on "Optimized stomatal conductance of vegetated land surfaces and its effects on simulated productivity and climate", Geophys. Res. Lett., 32, L08709, doi:10.1029/2005GL022355, 2005.

Kruijt, B., Malhi, Y., Lloyd, J., Nobre, A. D., Miranda, A. C., Pereira, M. G. P., Culf, A., and Grace, J.: Turbulence statistics above and within two Amazon rain forest canopies, BoundaryLayer Meteorol., 94, 297-331, 2000.

Kurc, S. A. and Small, E.E.: Dynamics of evapotranspiration in semiarid grassland and shrubland ecosystems during the summer monsoon season, central New Mexico, Water Resour. Res., 40, W09305, doi:10.1029/2004WR003068, 2004.

Lal, R.: Soil erosion and land degradation: the global risks, in: Advances in soil science, 11, Soil degradation, edited by: Lal, R. and Stewart, B. A., 129-172, Springer, New York, 1990.

Landau, L. D., Akhiezer, A. I., and Lifshitz, E. M.: General Physics., Mechanics and Molecular Physics, Nauka, Moscow, 1965.

Landau, L. D. and Lifshitz, E. M.: Course of Theoretical Physics, 6, Fluid Mechanics, 2nd ed., Butterworth-Heinemann, Oxford, 1987.

Lorenz, E. N.: The nature and theory of the general circulation 
of the atmosphere, World Meteorological Organization, Geneva, 1967.

L'vovitch, M. I.: World water resources and their future, American Geological Union, Washington, 1979

Mahrt, L., Lee, X., Black, A., Neumann, H., and Staebler, R. M.: Nocturnal mixing in a forest subcanopy, Agric. Forest Meteorol., 101, 67-78, 2000.

Makarieva, A. M., Gorshkov, V. G., and Li, B.-L.: Biochemical universality of living matter and its metabolic implications, Functional Ecol., 19, 547-557, 2005a.

Makarieva, A. M., Gorshkov, V. G., and Li, B.-L.: Revising the distributive networks models of West, Brown and Enquist (1997) and Banavar, Maritan and Rinaldo (1999): Metabolic inequity of living tissues provides clues for the observed allometric scaling rules, J. Theor. Biol., 237, 291-301, 2005b.

Makarieva, A. M., Gorshkov, V. G., and Li, B.-L.: Energetics of the smallest: Do bacteria breathe at the same rate as whales?, Proceedings of the Royal Society of London B, 272, 2219-2224, 2005c.

Marengo, J. A.: Interdecadal variability and trends of rainfall across the Amazon basin, Theor. Appl. Climatology, 78, 79-96, 2004.

McEwan, M. J. and Phillips L. F.: Chemistry of the atmosphere, Edward Arnold, London, 1975.

McGuffie, K. and Henderson-Sellers, A.: Forty years of numerical climate modelling, Int. J. Climatology, 21, 1067-1109, 2001.

McGuire, A. D., Prentice, I. C., Ramankutty, N., Reichenau, T., Schloss, A., Tian, H., Williams, L. J., and Wittenberg, U.: Carbon balance of the terrestrial biosphere in the twentieth century: Analyses of $\mathrm{CO}_{2}$, climate and land-use effects with four processbased ecosystem models, Global Biogeochem. Cycles, 15, 183206, 2001.

Miller, J. M., Williams, R. J., and Farquhar, G. D.: Carbon isotope discrimination by a sequence of Eucalyptus species along a subcontinental rainfall gradient in Australia, Funct. Ecol., 15, 222-232, 2001.

Nepstad, D., Lefebvre, P., da Silva, U. L., Tomasella, J., Schlesinger, P., Solorzano, L., Ray, P. M. D., and Benito, J. G.: Amazon drought and its implications for forest flammability and tree growth: a basin-wide analysis, Global Change Biol., 10, 704-717, 2004

Nesbitt, S. W. and Zipser, E. J.: The diurnal cycle of rainfall and convective intensity according to three years of TRMM measurements, J. Climate, 16, 1456-1475, 2003.

$\mathrm{Ni}$, J. and Zhang, X. S.: Climate variability, ecological gradient and the Northeast China Transect (NECT), J. Arid Environments, 46, 313-325, 2000

Nicholson, S. E.: The nature of rainfall variability over Africa on time scales of decades to millenia, Global Planet. Change, 26, $137-158,2000$

Oyama, M. D. and Nobre, C. A.: Climatic consequences of a largescale desertification in Northeast Brazil: A GCM simulation study, J. Climate, 17, 3203-3213, 2004.

Randel, D. L., Haar, T. H. V., Ringerud, M. A., Stephens, G. L., Greenwald, T. J., and Comb, C. L.: New global water vapor dataset, Bulletin of the American Meteorol. Society, 77, 12331254,1996
Savenije, H. H. G.: New definitions for moisture recycling and the relationship with land-use change in the Sahel, J. Hydrology, 167, 57-78, 1995.

Savenije, H. H. G.: Does moisture feedback affect rainfall significantly?, Physics Chem. Earth, 20, 507-513, 1996a.

Savenije, H. H. G.: The runoff coefficient as the key to moisture recycling, Journal of Hydrology, 176, 219-225, 1996b.

Savenije, H. H. G.: The importance of interception and why we should delete the term evapotranspiration from our vocabulary, Hydrol. Processes, 18, 1507-1511, 2004.

Shver, C. A.: Atmospheric precipitation on the territory of the USSR, Meteoizdat, Leningrad, 1976.

Shuttleworth, W. J.: Micrometeorology of temperate and tropical forest, Philosophical Transactions of the Royal Society of London B, 324, 207-228, 1989.

Shuttleworth, W. J., Gash, J. H. C., Lloyd, C. R., Moore, C. J., Roberts, J., Marques-Filho, A. O., Fisch, G., Filho, V. P. S., Ribeiro, M. N. G., Molion, L. C. B., Sa, L. D. A., Nobre, J. C. A., Cabral, O. M. R., Patel, S. R., and Carvalho, J. M.: Daily variations of temperature and humidity within and above Amazonian forest, Weather, 40, 102-108, 1985.

Smith, S. B.: Comments on "An interesting mesoscale stormenvironment interaction observed just prior to changes in severe storm behavior", Weather and Forecasting, 12, 368-372, 1997.

Szarzynski, J. and Anhuf, D.: Micrometeorological conditions and canopy energy exchanges of a neotropical rain forest (SurumoniCrane Project, Venezuela), Plant Ecol., 153, 231-239, 2001.

Tchebakova, N. M., Kolle ,O., Zolotoukhine, D., Arneth, A., Styles, J. M., Vygodskaya, N. N., Schulze, E.-D., Shibistova, O., and Lloyd, J.: Inter-annual and seasonal variations of energy and water vapor fluxes above a Pinus sylvestris forest in the Siberian middle taiga, Tellus B, 54, 537-551, 2002.

Tutin, C. E. G., White, L. J. T., and Mackanga-Missandzou, A. The use by rain forest mammals of natural forest fragments in an equatorial African Savanna, Conservation Biol., 11, 1190-1203, 1997.

Van de Koppel, J. and Prins, H. H. T.: The importance of herbivore interactions for the dynamics of African savanna woodlands: an hypothesis, J. Tropical Ecol., 14, 565-576, 1998.

Weaver, C. P. and Ramanathan, V.: Deductions from a simple climate model: Factors governing surface temperature and atmospheric thermal structure, J. Geophys. Res., 100D, 11585 $11591,1995$.

Webber, S. R. and Wilmott, C. J.: South American Precipitation: 1960-1990 gridded monthly time series (version 1.02), Center for Climatic Research, Department of Geography, University of Delaware, Newark, Delaware, 1998.

Werth, D. and Avissar, R.: The regional evapotranspiration of the Amazon, J. Hydrometeorol., 5, 100-109, 2004.

Zhou, J. and Lau, K.-M.: Does a monsoon climate exist over South America?, J. Climate, 11, 1020-1040, 1998. 